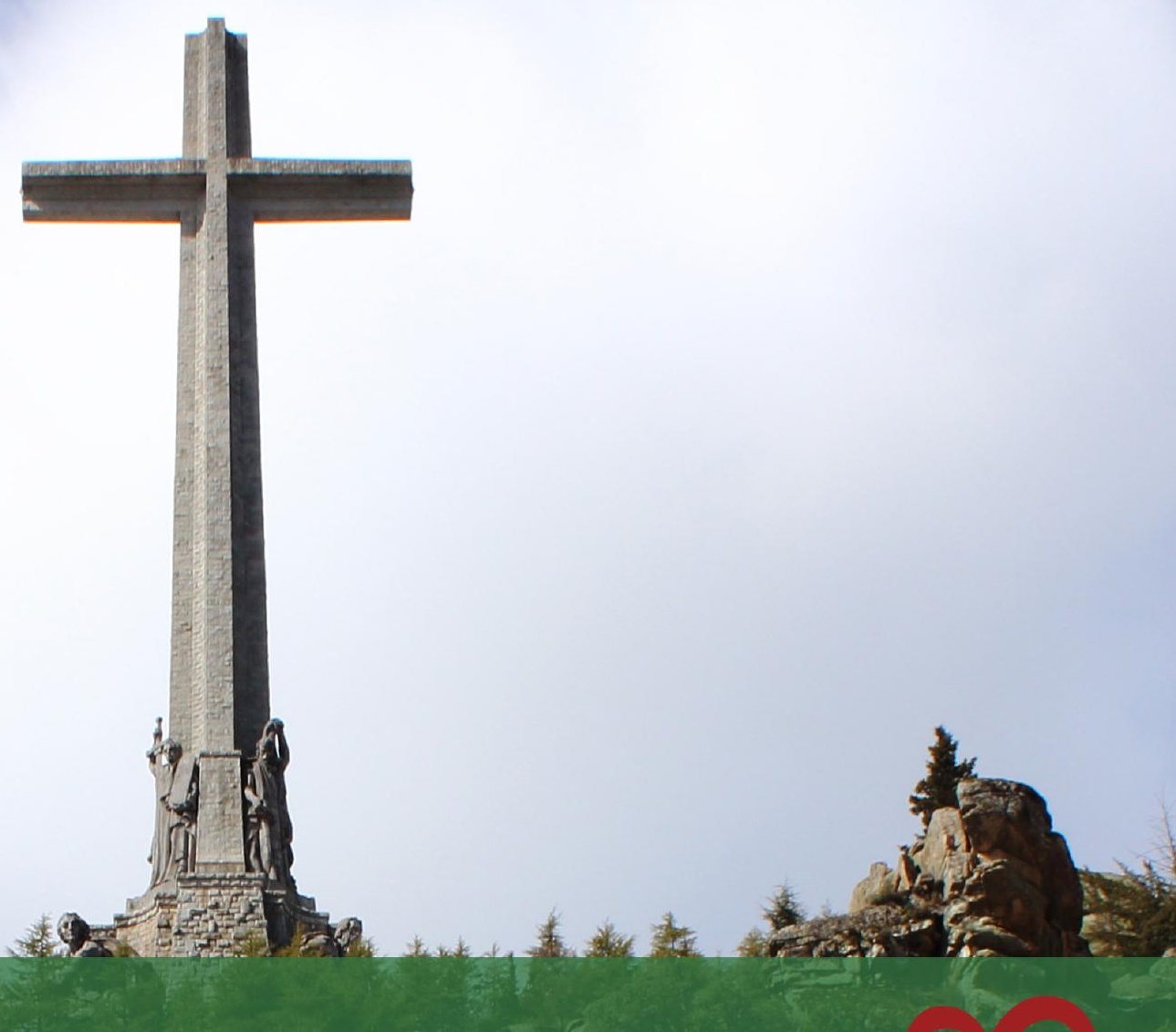

Revista digital de Ciencia y Didáctica de la Historia

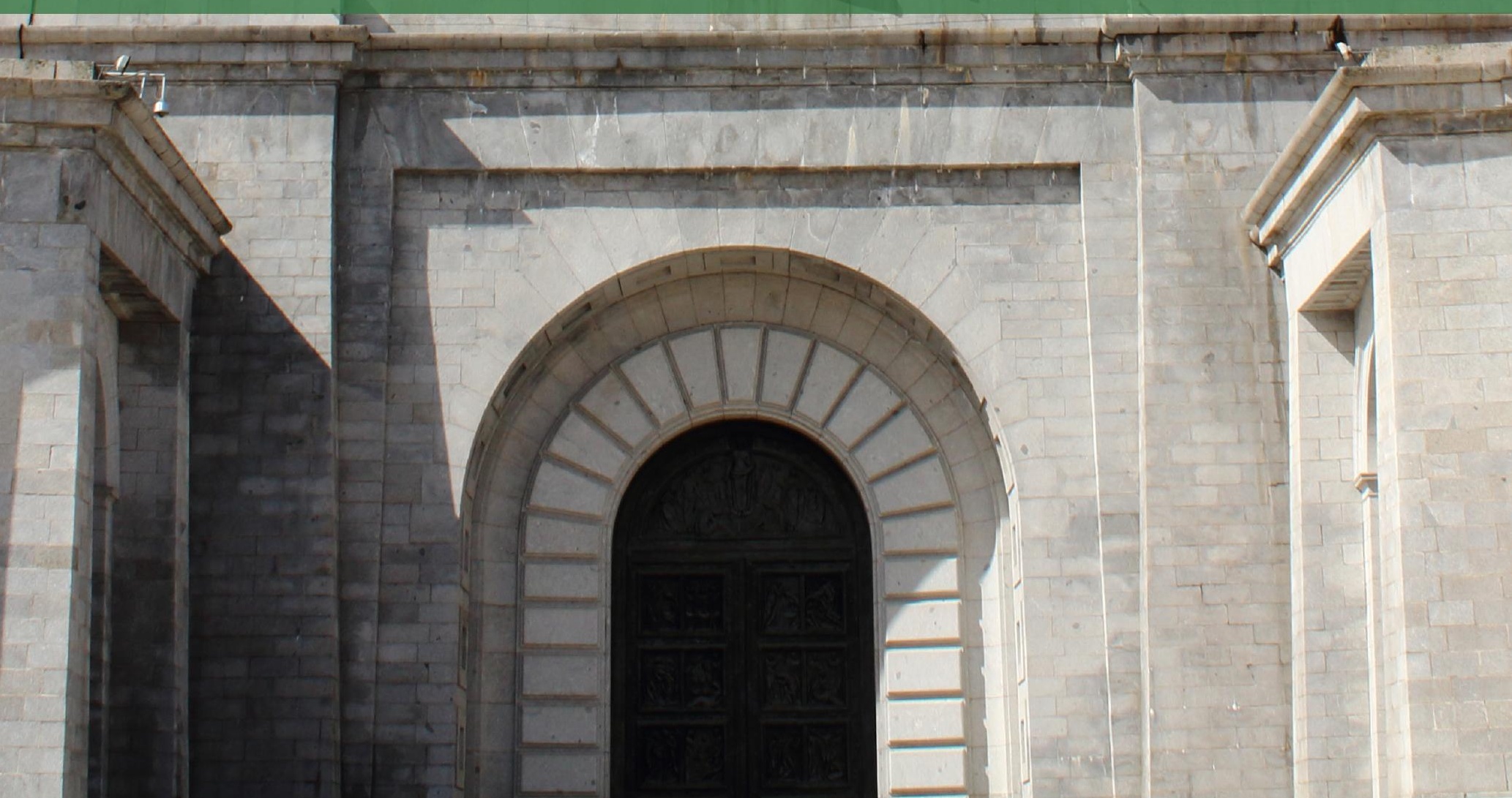




\section{Panta Rei \\ Revista Digital de Ciencia \\ y Didáctica de la Historia}

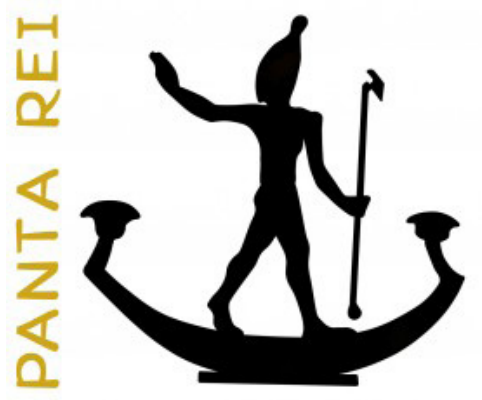

\section{8}

Revista anual

Fecha de inicio: 1995

Revista Panta Rei. pantarei@um.es

Edita:

Centro de Estudios del Próximo Oriente y la Antigüedad Tardía - CEPOAT

Edificio Universitario Saavedra Fajardo.

Universidad de Murcia

C/ Actor Isidoro Máiquez, 9

30007 - MURCIA - ESPAÑA

Teléfono: (+34) 868883890

cepoat@um.es

Web: www.um.es/cepoat/pantarei

Edición 2018

ISSNe: 2386-8864

ISSN: 1136-2464

Depósito legal: MU-966-1995

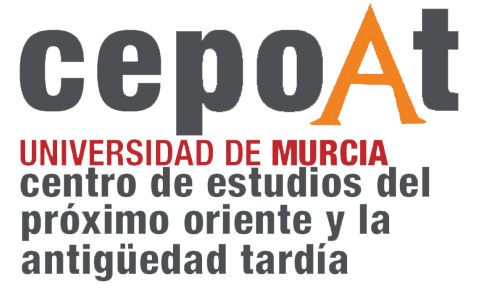

En Portada: Valle de los Caídos, Madrid. (Fotografía de: Adrián Rosell Lucas).

Responsables de los textos: Sus autores.

Responsable de la presente edición: Consejo Editorial Panta Rei. 


\section{CONSEJO DE REDACCIÓN}

\section{Coordinador editorial}

Egea Vivancos, Alejandro

[Didáctica de las Ciencias Sociales, UMU]

\section{Editores}

Botí Hernández, Juan Jesús

[CEPOAT, UMU]

Jiménez Vialás, Helena

[UMU]

López Muñoz, Damaris

[UJA]

Meseguer Gil, Antonio José

[CEPOAT, UNED]

Sáez Giménez, David Omar

[CEPOAT, UMU]

Sánchez Mondéjar, Celso Miguel

[Patrimonio Inteligente]

\section{Secretaria}

Arias Ferrer, Laura

[Didáctica de las Ciencias Sociales, UMU]

\section{Responsable informático}

Martínez García, José Javier

[CEPOAT, UMU]

\section{Traducción y corrección lingüística}

Martínez Martínez, Cristina

[Sociedad Española de Lenguas Modernas]

Albaladejo Albaladejo, Sara

[ISEN, UMU]

\section{CONSEJO ASESOR}

Adroher Auroux, Andrés María [Arqueología, Universidad de Granada]

Albero Muñoz, $\mathrm{M}^{\mathrm{a}}$ del Mar $\left[\mathrm{H} .^{\mathrm{a}}\right.$ del Arte, Universidad de Murcia]

Alia Miranda, Francisco [Historia Contemporánea, UCLM]

Arciniega García, Luis [Historia del Arte, Universidad de Valencia]
Barrio Barrio, Juan Antonio [Historia Medieval, Universidad de Alicante]

Castellano i Solé, Núria [Egiptología, Schola Didàctica Activa S.L.]

Chapman, Arthur [History Education, University College of London, Reino Unido]

Cid López, Rosa María [Historia Antigua, Universidad de Oviedo]

Cobacho López, Ángel [Derecho, Universidad de Murcia]

Cuenca López, José María [Didáctica de las Ciencias Sociales, Universidad de Huelva]

Egea Bruno, Pedro $\mathrm{M}^{\mathrm{a}}$ [Historia Contemporánea, Universidad de Murcia]

Feijoo Martínez, Santiago [Arqueología, Consorcio Ciudad Monumental de Mérida]

García Atienzar, Gabriel [Prehistoria, Universidad de Alicante]

Ginestí Rosell, Anna [Filología Clásica, Katholische Universität Eichstätt-Ingolstadt]

González Monfort, Neus [Didáctica de las Ciencias Sociales, Universidad Autónoma de Barcelona]

González Soutelo, Silvia [Arqueología, Universidad de Vigo]

Haber Uriarte, María [Prehistoria, Universidad de Murcia]

Hernández de la Fuente, David [Historia Antigua, Universidad Complutense]

Hutson, Scott R. [Anthropology, University of Kentucky, EEUU]

Igual Luis, David [Historia Medieval, UCLM]

Irigoyen López, Antonio [Historia Moderna, Universidad de Murcia]

Jover Maestre, Francisco Javier [Prehistoria, Universidad de Alicante]

Mahony, Simon [Digital Humanities, University College of London, Reino Unido]

Marsilla de Pascual, Francisco Reyes [Técnicas historiográficas, Universidad de Murcia]

Martínez-Burgos García, Palma [H. ${ }^{\text {a }}$ del Arte, UCLM]

Mathis, Christian [Didaktik der Geschichte, PH Zürich]

Miralles Maldonado, José Carlos [Filología Clásica, Universidad de Murcia]

Molina Gómez, José Antonio [Historia Antigua, Universidad de Murcia]

Mónica Ghirardi [Historia Moderna, Universidad Nacional de Córdoba, Argentina]

Navarro Espinach, Germán [Historia Medieval, Universidad de Zaragoza]

Noguera Celdrán, José Miguel [Arqueología, Universidad de Murcia]

Ortiz Heras, Manuel [Historia Contemporánea, UCLM]

Panzram, Sabine [Historia Antigua, Universität Hamburg]

Pérez Molina, Miguel Emilio [Filología Clásica, Universidad de Murcia]

Prados Martínez, Fernando [Arqueología, Universidad de Alicante]

Sánchez Ibáñez, Raquel [Didáctica de las Ciencias Sociales, Universidad de Murcia]

Sancho Gómez, Miguel Pablo [Educación, UCAM]

Victoria Moreno, Diego [Historia Contemporánea, UNED]

Vilar García, María José [Historia Contemporánea, Universidad de Murcia]

Vivas Sainz, Inmaculada [H. ${ }^{\text {a }}$ del Arte, UNED]

Zamora López, José Ángel [Próximo Oriente Antiguo, CCHS-CSIC] 

Artículos

El estilo decorativo en las primeras producciones cerámicas en el valle del río Vinalopó (Alicante).

Silvia Martínez Amorós.

Límites históricos del Ateísmo: increencia en la Grecia Antigua.

Ramón Soneira Martínez. .33

Dynamics of Power: an Architectural Reading of the Concentration of Power (Ullastret, 4th-3rd Century BC).

David Jesús Cebrián Martínez.

La mujer como exemplum. Subversión, desafío y resistencia en Valerio Máximo.

Lidia González Estrada.

The narrative framing of violence in teaching resources about the Spanish Conquest of America.

Ángela Bermúdez Vélez y Diego Argumero Martínez.

Modelos de conciencia histórica en el alumnado de Educación Secundaria: tradición, simbología y contextualización en torno a los restos del franquismo.

Diego Miguel-Revilla y María Sánchez Agustí.

La importancia de la contextualización curricular en la enseñanza de la Historia en México.

Enrique Bautista Rojas.

Experiencia didáctica para la enseñanza de la historia contemporánea a través de las fuentes en Educación Superior.

Nayra Llonch-Molina y Verónica Parisi-Moreno 161

\section{Reseñas}

Prados, F., Jiménez, H., Martínez, J.J. (Eds.) (2017). Menorca entre fenicis i púnics / Menorca entre fenicios y púnicos. Murcia: Centro de Estudios del Próximo Oriente y la Antigüedad Tardía de la Universidad de Murcia. 320 págs.

Pete Missingham

Bravo Bosch, M. J. (2017). Mujeres y símbolos en la Roma Republicana. Análisis jurídico-histórico de Lucrecia y Cornelia. Madrid: Dykinson. 333 págs.

Borja Méndez Santiago.

Karp, M. (2016). This Vast Southern Empire: Slaveholders at the Helm of American Foreign Policy. Cambridge: Harvard University Press. 360 pages.

Kevin Caprice.

Livi-Bacci, Massimo (2012). A Short History of Migration. Cambridge: Polity Press. 157 pages.

Alejandro Salamanca Rodríguez. 189

Normas de publicación/Publishing rules 



\title{
Modelos de conciencia histórica en el alumnado de Educación Secundaria: tradición, simbología y contextualización en torno a los restos del franquismo ${ }^{1}$
}

\author{
Historical Consciousness Models in Secondary Education Students: Tradition, \\ Symbology and Contextualization of the Remains of Franco's Regime
}

Miguel-Revilla, Diego ${ }^{2}$

Universidad de Valladolid

Sánchez-Agustí, María ${ }^{3}$

Universidad de Valladolid

Recibido: 18/12/2017

Aceptado: $20 / 06 / 2018$

Para citar este artículo: Miguel-Revilla, D., y Sánchez Agustí, M. (2018). Modelos de conciencia histórica en el alumnado de Educación Secundaria: tradición, simbología y contextualización en torno a los restos del franquismo. Panta Rei. Revista Digital de Ciencia y Didáctica de la Historia, $119-142$

ISSNe: $2386-8864$

DOI: $10.6018 /$ pantarei/2018/6

\section{Resumen}

El concepto de conciencia histórica, ligado con las concepciones del pasado y futuro en relación al presente, sirve como marco de análisis sobre las ideas del alumnado de Historia. La presente investigación ha contado con 132 estudiantes de cuarto curso de la ESO de cuatro ciudades españolas, con los que se ha trabajado en torno a la Transición española a través de un entorno digital de aprendizaje. Ante una problemática relacionada con la pervivencia de restos patrimoniales de la etapa franquista, y mediante un análisis cualitativo, el estudio centra su atención en caracterizar los modelos de conciencia histórica del alumnado. Los resultados identifican rasgos clave en sus concepciones, incluyendo la influencia de la tradición y una preocupación por la simbolización, corroborando además que la visión genealógica, ligada a la contextualización, es menos frecuente que las visiones tradicional, ejemplar y crítica.

\section{Palabras clave}

Educación, interpretación histórica, educación histórica, educación patrimonial, actitudes de los estudiantes.

1 La presente investigación queda enmarcada dentro del Proyecto HISREDUC ("La Historia reciente en la educación. Diseño y evaluación de entornos digitales de aprendizaje en la enseñanza secundaria de España y Chile"). Este proyecto, con referencia EDU2013-43782-P, ha sido financiado por el Ministerio de Economía, Industria y Competitividad (MINECO) del Gobierno de España.

2 Para contactar con el autor: Diego Miguel-Revilla. Universidad de Valladolid. dmigrev@sdcs.uva.es.

3 Para contactar con la autora: María Sánchez-Agustí. Universidad de Valladolid. almagosa@sdcs.uva.es. 


\begin{abstract}
The concept of historical consciousness, associated to past and future conceptions in relation to the present, is useful as an analytical framework focusing on history students' ideas. This paper has counted on the participating of 132 fourth-year compulsory secondary education students from four different cities in Spain, who have worked about the Spanish transition to democracy with a digital learning environment. Using a controversial issue linked with the continuity of patrimonial remains of the Francoist era, and by means of a qualitative analysis, this study centers its attention in characterizing students' historical consciousness models. The results help identify key characteristics in their conceptions, including the influence of tradition and a concern for symbolization, corroborating that the genetic vision, related to contextualization, is less common than the traditional, exemplary and critical ones.
\end{abstract}

\title{
Keywords
}

Education, historical interpretation, history instruction, heritage education, student attitudes.

\section{Introducción}

Los procesos de análisis e interpretación del pasado no pueden llevarse a cabo de forma aislada, sino que se entremezclan, de forma inherente, con dos aspectos fundamentales: la relación de los procesos históricos con el contexto actual, y la proyección realizada desde el presente hacia el futuro. En ambos casos, la Historia deja de lado su carácter puramente académico para adquirir un papel especialmente útil y relevante, otorgando significados a los procesos del presente, marcados por aspectos como los debates en torno a la recuperación de la memoria, el reconocimiento de actores del pasado, o la conquista simbólica de los espacios públicos.

Esta dualidad, según la cual el carácter científico de la disciplina histórica se combina estrechamente con sus diversas utilizaciones, es la que provoca que la orientación de la enseñanza de la Historia se haya convertido en un aspecto tan controvertido (Parra, 2017). Precisamente, esta característica es acentuada al trabajar sobre aquellas temáticas históricas ligadas de una u otra forma con la actualidad, especialmente en relación con aquellos debates más conflictivos o cercanos en el tiempo, que, por otro lado, ofrecen la posibilidad de ser aprovechados para promover un debate productivo sobre el posicionamiento de los estudiantes y sus concepciones más profundas.

Desde este punto de vista, no cabe duda de que la forma en la que se concibe el pasado puede condicionar aspectos tan variados como la identidad asumida por el alumnado, su percepción de pertenencia a colectivos, o la pervivencia en el tiempo de finalidades y valores, siempre a través de las narrativas construidas a su alrededor (López, Carretero, y Rodríguez-Moneo, 2014). En todo caso, el trabajo en torno a las concepciones del pasado puede resultar de utilidad para entender de qué manera los estudiantes orientan su aprendizaje y cómo se aproximan a los procesos del pasado, pero también para fomentar una reflexión sobre sus propias ideas, siempre con el interés de favorecer la comprensión de nuestro contexto.

\section{Fundamentación teórica}

El análisis de las concepciones interiorizadas por parte de los participantes en los procesos de enseñanza y aprendizaje de la Historia es complejo, ya sea orientado a las percepciones en torno a su objetivo y utilidad (Fuentes, 2004) o sobre la propia naturaleza de la disciplina (MiguelRevilla, Carril, y Sánchez-Agustí, 2017; VanSledright y Maggioni, 2016). Esta complejidad aumenta todavía más al interesarse por aspectos como la orientación histórica, donde el juego contextual y la capacidad de situación en el tiempo se entrelazan de manera potencialmente tortuosa.

En estas ocasiones, y ante la dificultad de percibir de una manera directa los conceptos que Koselleck describe como espacios de experiencia, es decir, el pasado hecho presente, y como 
horizontes de expectativa, su equivalente a través de una mirada hacia el futuro (Koselleck, 2004), la mediación a través de los restos materiales adquiere un sentido práctico. El examen crítico de los espacios del pasado y su simbología se convierte así en una actuación con capacidad para sacar a la luz estas visiones acerca del pasado, proporcionando un marco para buscar vestigios de las tipologías de conciencia histórica existentes entre un alumnado que todavía está construyendo su capacidad orientadora.

\subsection{Usos del pasado y orientación en el tiempo}

Uno de los aspectos característicos de la Historia tiene que ver con su dualidad, por la cual es posible distinguir con claridad elementos ligados al propio marco disciplinar (conceptos y teorías, métodos de investigación y formas de representación propias del análisis del pasado), siempre en paralelo a aspectos propios de la vida práctica. Esta conceptualización, reflejada en la matriz disciplinar propuesta por Rüsen (2005), muestra la importancia de la orientación proporcionada por el análisis del pasado, algo sintetizado en dos aspectos concretos: las funciones percibidas que la Historia puede llegar a ofrecer, y los intereses que ésta promueve, desde el punto de vista de la actuación en el presente dirigida al futuro.

Los usos de la Historia no pueden, por tanto, dejarse de lado a la hora de examinar de qué forma se trabaja acerca del pasado en las aulas, ni de qué manera afectan a las concepciones del alumnado. La investigación en torno al tratamiento de la enseñanza de los procesos históricos asume, de esta manera, la necesidad de establecer si únicamente se presta atención a los aspectos disciplinares y ligados a lo cognitivo, dejando de lado las representaciones mentales, o si, por el contrario, se centra toda la atención en los aspectos relacionados con las funciones de la Historia (Chapman, 2014). De hecho, tal y como critica Lee (2002), es posible separar la función otorgada al pasado a través de los procesos de orientación, de la propia Historia como disciplina, aunque aquí merezca la pena recordar el papel y los condicionamientos de los intereses y de la memoria en los propios procesos de construcción de los relatos históricos (Ricoeur, 2004; Traverso, 2007).

De forma específica, el uso del patrimonio y de los espacios públicos se configura como un proceso ligado claramente a la orientación, fomentando el establecimiento de los lugares de memoria descritos por Nora (1989), donde el espacio físico asume un carácter plenamente simbólico, pese a las transformaciones y recontextualizaciones provocadas por el paso del tiempo, y donde los significados pierden su carácter fijo (Lowenthal, 1998). Asumido, por tanto, el carácter no neutro de esta serie de emblemas de valores supuestamente colectivos o compartidos, éstos se convierten en el foco de un análisis capaz de aportar información acerca de los posicionamientos personales ante su presencia.

En la práctica, el patrimonio y los significados otorgados por los estudiantes a estos lugares han sido examinados en experiencias empíricas diversas, como las llevadas a cabo en la localidad de Guimarães (Portugal), donde adolescentes trabajaron en torno a los espacios públicos y edificios representativos de la ciudad (Pinto, 2016); en Ottawa (Canadá), donde se analizó el sentimiento de pertenencia nacional de estudiantes universitarios y de Educación Secundaria (Lévesque, Croteau, y Gani, 2015); o en la Columbia Británica (Canadá), donde, tomando como foco polémicas como la presencia de murales con varias décadas de antigüedad con representaciones de escenas específicas del pasado nacional, se analizaron las ideas de estudiantes sobre la pervivencia de estos símbolos (Seixas y Clark, 2004). En todos estos casos se utilizó el concepto de conciencia histórica, aunque de forma bastante diferenciada, como eje central para la comprensión de las percepciones de los estudiantes, y de ahí que merezca la pena examinar esta idea con más detenimiento.

\subsection{La conciencia histórica como objeto de análisis}

La conciencia histórica, entendida de forma genérica como "una conexión entre la interpretación del pasado, la comprensión del presente y la perspectiva del futuro" (Jeismann, 1997, 
p. 42; citado en Rüsen, 2001) adquiere utilidad, por tanto, como marco teórico mediante el cual analizar las concepciones presentes en el alumnado de Historia, con el objetivo de orientar su aprendizaje y adaptar los procesos de enseñanza.

Originaria del mundo germánico en su expresión actual, la idea de conciencia histórica ha sido conceptualizada y aplicada con una larga tradición desde la década de 1970, jugando un papel relevante en el contexto educativo alemán (Ahonen, 2005), donde ha servido para orientar la educación histórica hacia el trabajo en torno a los conceptos disciplinares y sobre la identidad, más que hacia la mera transmisión del conocimiento (Körber, 2017). A pesar de que su influencia haya tardado en penetrar en otros ámbitos geográficos, ésta se ha dejado notar en las últimas dos décadas, tanto en ámbitos anglosajones (Seixas, 2004) como en el contexto iberoamericano (Santisteban, 2017).

Identificada inicialmente con la capacidad o privilegio del mundo contemporáneo para ser consciente de la historicidad de todo aquello que le rodea (Gadamer, 1975), la conciencia histórica comenzó a ajustar su andamiaje teórico con las propuestas de Jeismann, Pandel y Rüsen, siendo este último quien elaboró una de las fundamentaciones más citadas e influyentes (Kölbl y Konrad, 2015). A partir de un marco central, donde relaciona elementos ligados a la experiencia temporal, a la interpretación del pasado desde el presente y a la orientación para la actuación de cara al futuro, añadiendo además características relacionadas con la moralidad, Rüsen (2005) identifica modelos concretos de conciencia histórica, capaces de ser analizados a través del examen de las narrativas, donde pueden quedar expresadas ideas ligadas a la identidad y las concepciones profundas de los estudiantes (Bermúdez, 2012).

La conceptualización de Rüsen, utilizada para la realización de la presente investigación, categoriza los modelos de conciencia histórica en tradicional, ejemplar, crítico y genealógico, según rasgos centrados en la percepción de las relaciones entre pasado, presente y futuro. Cada una de las cuatro visiones está marcada, respectivamente, por una preocupación por la tradición y su permanencia, la búsqueda de reglas comunes o ejemplares, la ruptura y crítica de lo establecido, o la comprensión de la historicidad de nuestros contextos, y siempre con diferentes concepciones ligadas a la interpretación, la experiencia, la orientación y la moralidad en la Historia. En palabras de Rüsen, "la conciencia histórica evoca el pasado como un espejo de experiencia dentro del cual la vida del presente se ve reflejada, y sus características temporales reveladas" (Rüsen, 2004, p. 67), y es este reflejo, diferente para cada persona, el que marcará, según esta tipología, cómo entender su papel en el devenir histórico y cómo orientar su actuación en el presente.

La utilización de la conciencia histórica como categoría de análisis se presenta, de esta manera, como una posibilidad especialmente interesante cuando se combina con el examen del patrimonio o de cualquiera de los restos del pasado, sobre todo en aquellos casos en los que éstos han adquirido un fuerte carácter simbólico. Desde el punto de vista de la enseñanza y el aprendizaje de la Historia, el peso de los significados puede ser trabajado de múltiples formas, incorporando los aspectos ligados tanto a la interpretación y los usos sociales y políticos, como a los análisis desde categorías disciplinares a través de los conceptos de segundo orden. La conciencia histórica, capaz de relacionarse con facilidad con el trabajo en torno al pensamiento histórico (Duquette, 2015), puede convertirse, por tanto, en un instrumento útil en un doble sentido: favoreciendo la reflexión sobre las concepciones propias y permitiendo un análisis crítico de las mismas, y es sobre esta primera parte donde se hace hincapié desde este estudio específico.

\section{Diseño de la investigación}

\subsection{Objetivo y enfoque metodológico}

Asumiendo el interés por examinar en profundidad las concepciones presentes en el alumnado de Educación Secundaria en torno a su orientación histórica, la presente investigación establece como objetivo principal examinar los modelos de conciencia histórica detectados 
en estudiantes de Historia de cuarto curso de la ESO. Partiendo de la tipología establecida por Rüsen (2005), y ayudándose de experiencias previas centradas en otros contextos con diseños de investigación similares (Seixas y Clark, 2004), se hace uso del patrimonio histórico, y de los restos materiales y simbólicos que se conservan de la época franquista, como eje central para examinar las percepciones mentales del alumnado.

Este estudio adquiere un enfoque metodológico puramente cualitativo, ya que se centra en el análisis de las narrativas asumidas por estudiantes de Historia, y por tanto, de los procesos históricos identificados como propios, aspectos dependientes de las diferentes formas de experiencia en cada contexto (Gay, Mills y Airasian, 2012). Entendiendo como esenciales la naturaleza interpretativa de la investigación y sus rasgos experienciales, tanto desde el punto de vista personal como en lo ligado a lo social, el presente estudio se interesa por el análisis de la subjetividad de los participantes, elemento esencial para lograr introducirse en el campo de las concepciones y representaciones (Stake, 2010).

\subsection{Contexto y participantes}

La investigación centra su atención en una serie de intervenciones en cuatro Institutos de Educación Secundaria de otras tantas localidades españolas (Valladolid, Portillo, Burgos y Oviedo) durante los meses de mayo y junio de 2017. Durante este proceso, y a lo largo de siete sesiones, un total de 132 estudiantes de la asignatura Geografía e Historia de cuarto curso de Educación Secundaria Obligatoria trabajaron y fueron evaluados en torno a la transición a la democracia en España. Durante todo este proceso se hizo uso de un entorno digital de aprendizaje, diseñado de forma expresa para desarrollar habilidades relacionadas con el pensamiento histórico en el alumnado a través del uso de actividades específicas ligadas a fuentes históricas de la época.

La unidad didáctica dedicada a la Transición fue elaborada por los autores e integrada dentro del propio entorno digital. Éste fue utilizado durante cinco de las siete sesiones, dedicando cada una de ellas a temáticas diferentes. La primera sesión, dedicada a los conocimientos básicos del alumnado sobre el periodo, se complementó con la segunda, centrada en el cambio social y cultural de la sociedad española en la década de 1970. En la tercera sesión se trabajó sobre el ambiente político, la inestabilidad y la represión, mientras que la cuarta estuvo dedicada al proceso político y la ruptura pactada, trasladando el debate sobre los frutos del consenso y su revisión desde el presente a la quinta y última sesión.

Todas estas temáticas se pusieron siempre en relación con el desarrollo de aspectos como la identificación de la significatividad histórica, el trabajo en torno al cambio y la continuidad o la perspectiva histórica, así como el resto de las dimensiones que caracterizan el pensamiento histórico (Seixas y Morton, 2013). Los aspectos ligados a la memoria histórica y los restos de la etapa franquista no se introdujeron hasta la última sesión, una vez que el alumnado contara con información suficiente sobre el contexto para realizar la actividad.

Los 132 estudiantes (70 alumnas y 62 alumnos con edades comprendidas entre los 15 y 16 años) que participaron en la experiencia pertenecen a seis grupos diferenciados distribuidos de la siguiente forma: un grupo en Valladolid, dos grupos en Portillo, dos grupos en Burgos y un último grupo en Oviedo. Cada uno de estos grupos trabajó de forma presencial con versiones equivalentes de la unidad didáctica integrada en el entorno digital, y de forma paralela en el tiempo, al hacer coincidir las intervenciones con la parte final de la asignatura, momento en el que se abordan con mayor frecuencia las temáticas propias de la Historia reciente.

Se trata de una muestra intencional, justificada porque los cuatro centros cuentan con un profesorado de Ciencias Sociales abierto a experiencias de innovación docente y con tradición investigadora en colaboración con los departamentos didácticos universitarios, así como por la existencia en todos ellos de un alumnado con características socioeconómicas y académicas equiparables. Por último, la selección de cuarto curso de la ESO tiene como razón de ser que es el único momento de la Educación Secundaria Obligatoria en la que se tratan temáticas propias 
de la Historia más cercana, y por tanto, la única ocasión en la que puede trabajarse en torno al franquismo y la transición a la democracia.

\subsection{Obtención, procesamiento y análisis de la información}

\section{a. Procedimiento y obtención de la información}

Las respuestas proporcionadas por los participantes y analizadas en este estudio fueron obtenidas en la última de las sesiones programadas para la intervención. Tras haber orientado el trabajo realizado en días anteriores a aspectos ligados con la evolución de la vida cotidiana, la sociedad o la economía durante la época de la Transición, así como sobre el terrorismo y la búsqueda del consenso político, se planteó a los alumnos participar en una actividad en la que se trabajaría sobre los restos aún vigentes de la etapa franquista.

Tras dedicar una parte de la sesión a revisar el debate en torno a nombres de calles, monumentos y símbolos todavía presentes en España, ligándolo de forma concreta con las distintas localidades en las que están situados los centros, así como con los debates presentes en los medios de comunicación durante el periodo de la intervención, se pidió a los alumnos y alumnas que participaran en un ejercicio integrado en el entorno. En dicha actividad, los participantes tuvieron que argumentar qué uso dar al Valle de los Caídos si de ellos dependiera la decisión, planteándoles el problema de esta manera:

El Valle de los Caídos es un conjunto monumental construido en la provincia de Madrid tras la Guerra Civil. En este espacio no sólo está enterrado Franco y el fundador de la Falange, José Antonio Primo de Rivera, sino también más de 30.000 soldados de ambos bandos.

El conjunto pertenece a Patrimonio Nacional, pero es muy polémico, al ser percibido como un símbolo de la victoria del franquismo y hay un debate sobre qué hacer con él o qué utilidad darle.

En este caso, te pedimos que escribas de una forma algo extensa qué harías tú con un monumento como éste, teniendo en cuenta que forma parte de la Historia de España. Nos interesa que expliques las razones y argumentos por las que defiendes una posición u otra, ya que no hay una respuesta correcta o incorrecta.

El instrumento utilizado para la obtención de la información es, por tanto, una pregunta parcialmente guiada, pero de respuesta completamente abierta, integrada en el entorno dentro de la sesión correspondiente de la unidad didáctica trabajada. Los estudiantes dedicaron alrededor de la mitad de la duración de la sesión a la realización de esta actividad, redactando y mandando sus respuestas en línea a través de los mecanismos ofrecidos por la plataforma de aprendizaje basada en Moodle, tal y como puede observarse en la Figura 1 y la Figura 2.

Es importante resaltar que, pese a contar con 132 participantes, el hecho de que tuviera que hacerse uso de las salas de informática de los distintos centros obligó a que el alumnado tuviera que agruparse y trabajar en el entorno por parejas. De esta forma, las respuestas enviadas a través de la plataforma digital son 73 en total, habiendo sido redactadas y consensuadas en grupos de dos personas de forma mayoritaria. 


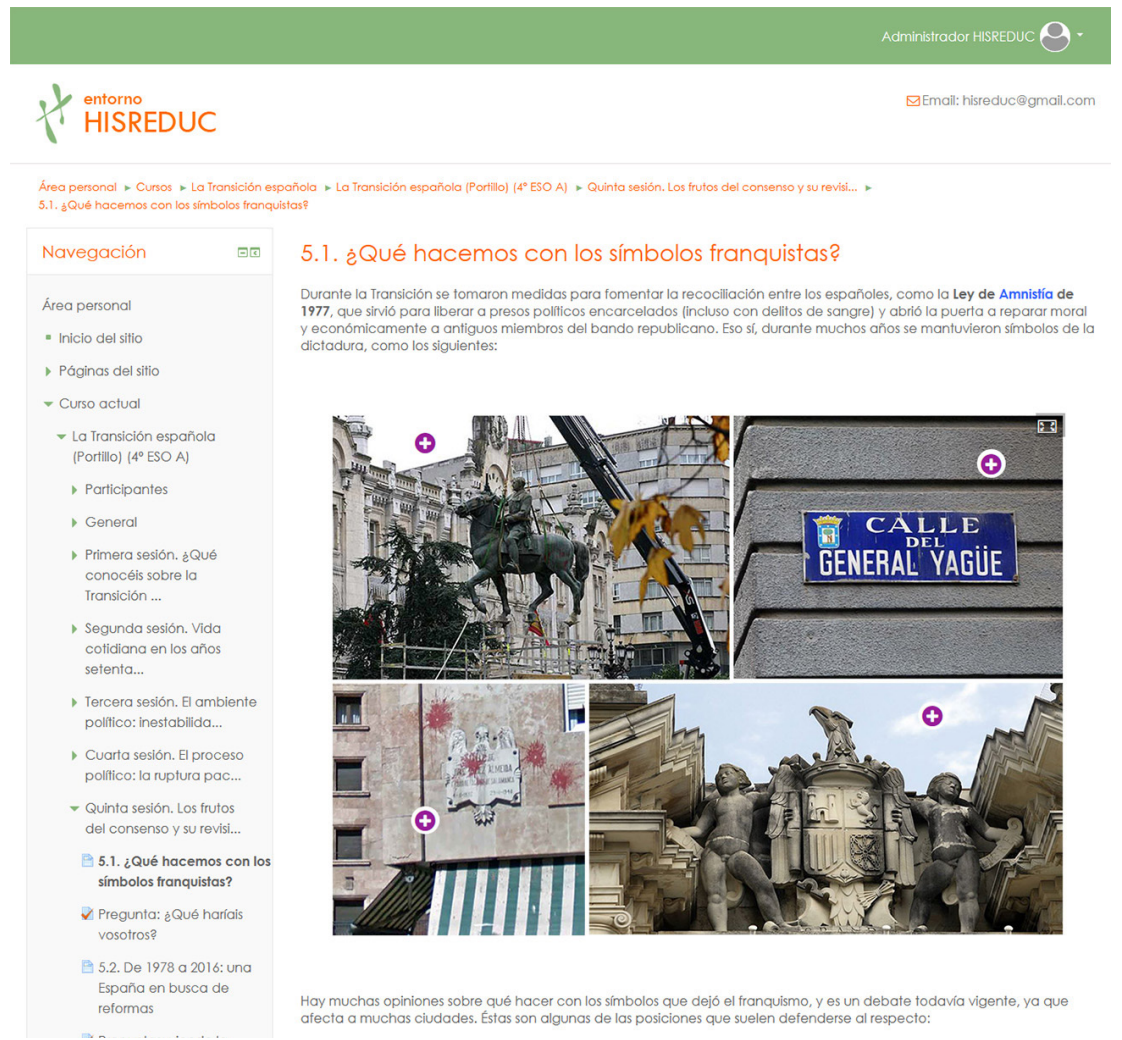

Figura 1: actividad integrada en la quinta sesión del entorno de aprendizaje y centrada en los símbolos de la etapa franquista. Fuente: elaboración propia.

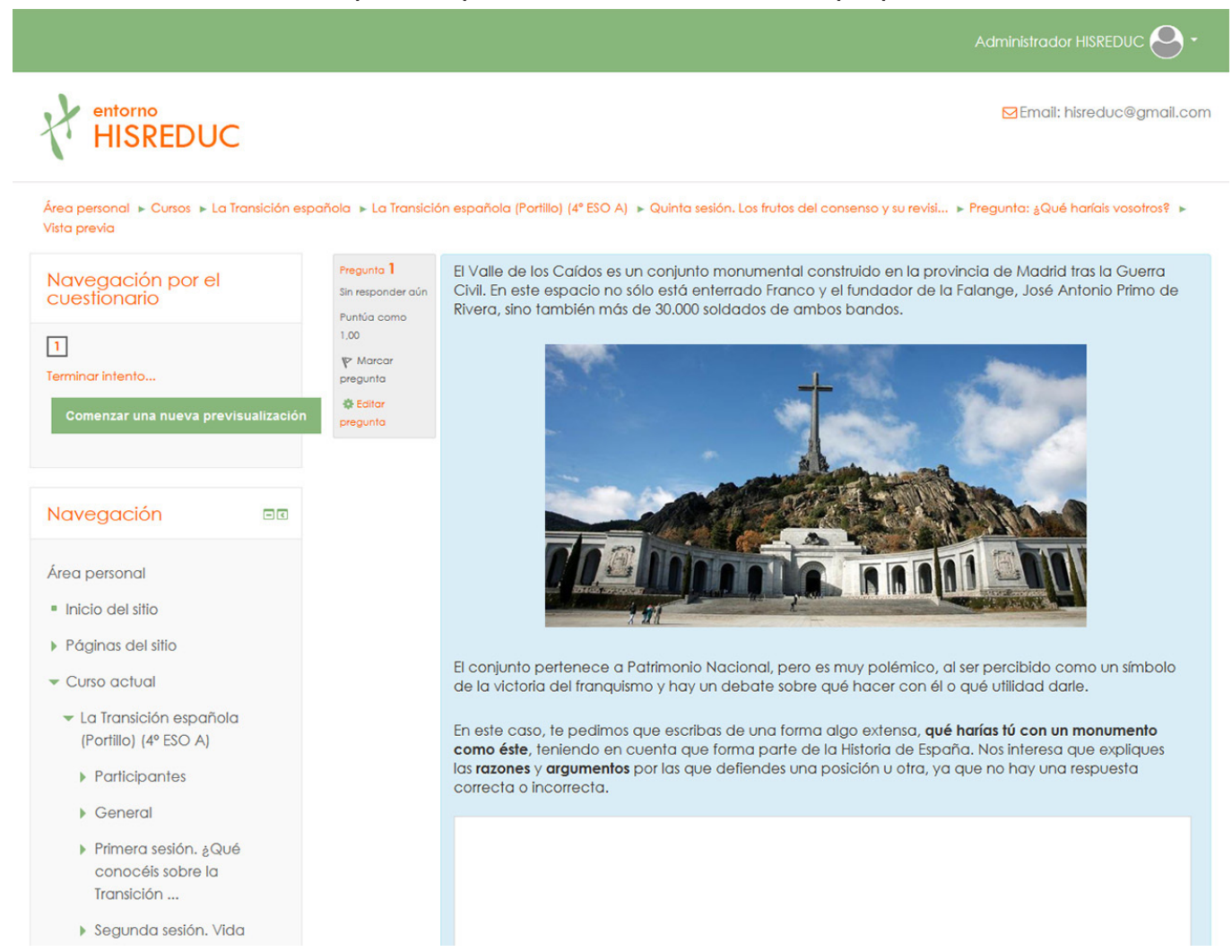

Figura 2: cuestionario integrado en el entorno de aprendizaje utilizado para obtener las visiones del alumnado. Fuente: elaboración propia. 


\section{b. Procesamiento y análisis de la información}

Las respuestas enviadas por los estudiantes y almacenadas en el entorno digital de aprendizaje han sido exportadas de la plataforma con el objetivo de ser procesadas y posteriormente codificadas. Para este procedimiento se ha hecho uso, en primer lugar, de ATLAS.ti como herramienta de análisis cualitativo, utilizándose posteriormente SPSS como un instrumento secundario a través del cual poder cuantificar de forma descriptiva las categorías en las que se han agrupado los datos obtenidos.

Cada uno de los textos redactados y enviados por los participantes ha sido tratado como una expresión de narrativas específicas, pero también como una ventana a través de la cual observar algunos de los rasgos fundamentales que caracterizan las diferentes visiones ligadas a la conciencia histórica, tal y como puede observarse en la Tabla 1. La tipología elaborada por Rüsen (2005), donde se diferencia entre los modelos o visiones tradicional, ejemplar, crítica o genealógica, ha sido utilizada como eje central a la hora de establecer esta categorización.

Tabla 1

Características generales de los diferentes modelos de conciencia histórica según la tipología elaborada por Rüsen (2005)

\begin{tabular}{ll}
\hline Modelo de & Características generales \\
conciencia histórica & \\
\hline Visión tradicional & - Basada en búsqueda de los orígenes para su persistencia a lo largo \\
& del tiempo, incluido el presente. \\
& - Incidencia en la pervivencia de elementos preexistentes como \\
& necesarios para la identidad actual, en un tiempo estacionario. \\
\hline Visión ejemplar & - Centrada en la identificación de principios y reglas, válidas para todo \\
& tipo de contexto histórico. \\
& - Búsqueda de ejemplos o guías en el pasado que se ajusten al modelo \\
& establecido, con una proyección también hacia el futuro. \\
\hline Visión crítica & - Contestación a los modelos o estructuras tradicionales basadas en la \\
& continuidad. \\
& - La identidad tradicional es diluida para lograr una nueva, basada en la \\
& contrariedad y en una idea del tiempo como objeto de juicio. \\
\hline Visión genealógica & - Naturalización de los procesos de transformación como dinámicos e \\
& inherentes al proceso temporal. \\
& - Autodefinición mediante un mestizaje integrador de cambio y \\
& continuidad en un contexto de comprensión del tiempo histórico.
\end{tabular}
Fuente: elaboración propia a partir de Rüssen (2005).

El análisis de las respuestas se ha centrado en la diferenciación, también propuesta por Rüsen, entre aquellos aspectos ligados a la experiencia, la interpretación, la orientación y, por último, relacionados con la moralidad. Los rasgos esenciales de cada uno de estos elementos, para cada uno de los modelos concretos de la conciencia histórica, son identificados con detalle en el análisis de los resultados obtenidos. En todo caso, es importante recalcar que, desde el punto de vista de esta investigación específica, los diferentes modelos de conciencia histórica no corresponden a niveles de progresión, ya que en ningún caso se da por hecho que una visión sea más deseable que otra, o que para asumir las características de uno de los modelos sea necesario pasar por otro de ellos de forma intermedia, a pesar de que Rüsen indique que es teóricamente posible establecer 
precondiciones y detectar un aumento de la "complejidad en torno a varios aspectos" en el paso de una categoría a otra (Rüsen, 2004, p. 79).

De esta manera, el proceso de codificación, realizado por los propios autores, ha partido de una serie de categorías identificadas a priori, pero se ha completado mediante un análisis centrado en la búsqueda de categorías emergentes (Corbin y Strauss, 2008). En el primero de los procesos, la diferenciación establecida, según las diversas visiones, entre las características relacionadas con la moralidad, experiencia, interpretación y orientación, sirve de guía para categorizar ideas centrales presentes en las narrativas. Pese a que no todos los textos, generalmente por su extensión, son capaces de mostrar todos los rasgos identificados por Rüsen al mismo tiempo, sí es posible establecer la predisposición de su autor atendiendo a su incidencia en aspectos como el mantenimiento de la tradición, la búsqueda de lecciones, la tendencia a refutar marcos establecidos o la predisposición por la contextualización.

Es precisamente en este momento donde las categorías emergentes asumen una función de gran utilidad, ya que no solamente hacen posible encontrar rasgos comunes entre las respuestas, sino que sacan a la luz ideas que facilitan la interpretación del conjunto de las respuestas y, sobre todo, muestran elementos que son compartidos de forma exclusiva o están ausentes en su conjunto en cada uno de los diferentes modelos de la conciencia histórica. Aspectos de algunas de estas visiones que se discutirán con más detalle en secciones posteriores, como la preocupación por la simbología, la concepción del pasado como parte inamovible de la Historia, o la incidencia en la reivindicación, aparecen y son categorizadas de esta manera.

En definitiva, la categorización dual pretende centrar la atención en los rasgos identificativos del marco teórico utilizado y ligado a la conciencia histórica, pero sin olvidar los elementos propios del contexto en el que se desarrolla la investigación, así como de la temática específica sobre la que los estudiantes trabajan.

\section{Resultados}

Tras el análisis de la información proporcionada por los participantes, y tras categorizar cada una de las respuestas en las diferentes tipologías de conciencia histórica (73 respuestas correspondientes a 132 estudiantes), los resultados muestran una distribución desigual, según puede observarse en la Tabla 2, en la que una mayoría de estudiantes (en torno a un 36 por ciento) se encuadra en una visión de tipo ejemplar. Las visiones tradicionales y críticas, asumidas por algo más de un 27 por ciento de los participantes cada una, adquieren un peso equivalente, mientras que la visión genealógica es elegida de forma minoritaria por poco más de un 8 por ciento del alumnado. Por otro lado, una de las respuestas analizadas no fue categorizada, al entender que no existía información suficiente para poder ligarla con una de las cuatro visiones de forma específica.

Tabla 2

Distribución de las respuestas analizadas según los diferentes modelos de conciencia histórica

Respuestas analizadas

$(n=73)$

\begin{tabular}{llcr} 
& & $\mathrm{n}$ & $\%$ \\
\hline & Visión tradicional & 20 & 27.4 \\
Modelo de & Visión ejemplar & 26 & 35.6 \\
conciencia & Visión crítica & 20 & 27.4 \\
histórica & Visión genealógica & 6 & 8.2 \\
& Sin clasificar & 1 & 1.4 \\
\hline
\end{tabular}

Fuente: elaboración propia. 
Esta distribución, en la que se toma en cuenta el conjunto de las respuestas, no difiere en lo esencial de la que es posible observar en cada uno de los seis grupos en los que se produjo de la intervención. En cuatro de ellos, la visión ejemplar es la mayoritaria, siendo la visión crítica la más predominante en el grupo ovetense y en uno de los grupos burgaleses, aunque por poca diferencia en este último caso. En todo caso, la visión genealógica es la más elusiva, llegando a no estar ni siquiera presente en dos de los grupos con los que se trabajó.

A pesar de todo, el análisis de las respuestas indica que éstas no son siempre completamente coherentes con una de las visiones, encontrándose en multitud de ocasiones rasgos procedentes de diferentes modelos de conciencia histórica. De esta manera, es perfectamente posible encontrar esbozos de distintas concepciones, incluso a veces contrapuestas, razón por la que es conveniente matizar la distribución encontrada, y que tenga más valor examinar con profundidad las opiniones recogidas, algo que se realiza a continuación mediante un agrupamiento según visiones.

\subsection{Visión tradicional}

Entendida como una concepción del devenir histórico en el que el presente queda ligado estrechamente al pasado en busca de continuidades y permanencias, el modelo de conciencia histórica identificado por Rüsen como tradicional asume una serie de rasgos identificadores (Tabla 3) que son reconocidos entre las respuestas proporcionadas por los participantes.

Tabla 3

Rasgos identificadores del modelo tradicional atendiendo a la experiencia, interpretación, orientación y moralidad, de acuerdo con la caracterización de Rüsen (2005)

Rasgos identificadores del modelo tradicional

Experiencia: concepción estática del tiempo.

Interpretación: pasado como determinante de obligaciones presentes.

Orientación: mantenimiento de la tradición.

Moralidad: reconocimiento en el marco moral de la tradición.

Fuente: elaboración propia a partir de Rüssen (2005).

De forma general, aquellos estudiantes que asumen este modelo de conciencia histórica enfocan la problemática que se les presenta, es decir, qué hacer con el Valle de los Caídos, desde un punto de vista en el que el presente se considera como una herencia directa del pasado, y donde los actores históricos asumen un papel de continuadores de la tradición. No es de extrañar, por tanto, que la enorme mayoría de las respuestas ligadas con la visión tradicional no entiendan como deseable otra posibilidad que no sea la conservación del conjunto monumental tal y como existe en la actualidad, algo que también se extiende en algunas respuestas al conjunto de símbolos y restos de la etapa franquista.

Por supuesto, este posicionamiento no tiene que ver completamente, al menos de forma directa, con el grado de simpatía o rechazo despertado por este periodo entre el alumnado, sino más bien con su forma de concebir la relación entre el pasado y el presente. De ahí que tenga interés no centrar el análisis en los aspectos más ligados a la ideología política, sino en las opiniones de los participantes en torno a los procesos de representación y simbolización de la Historia. Por esta razón merece la pena atender a los argumentos utilizados en las distintas respuestas, ya que son los que permiten entender con claridad los enfoques existentes y discriminar adecuadamente entre los diferentes modelos de conciencia histórica. 


\section{a. El pasado como parte de la Historia}

Tanto las respuestas encuadradas en el modelo tradicional como aquellas ligadas al modelo ejemplar coinciden en observar el pasado desde una perspectiva en la que los lazos con el presente se advierten como extremadamente fuertes, e incluso como condicionantes para las actuaciones que realizamos desde nuestro contexto temporal. Por supuesto, pese a las diferencias detectables entre las visiones tradicional y ejemplar, y que quedan patentes tras este análisis, se mantiene como nexo común un punto de vista en la que el pasado es "parte de la Historia".

De las 41 referencias a esta idea presentes en el total de 73 textos, 38 de ellas se agrupan en las visiones tradicional y ejemplar, mientras que solamente en tres de las respuestas encuadradas en las otras visiones se utiliza este argumento.

[G3.32] Este monumento forma parte de la Historia de España como muchos otros monumentos aunque tengan otros símbolos y si los otros monumentos no se han quitado, ¿por qué sí que debería de quitarse este? Al fin y al cabo ese monumento representa un acontecimiento que ha ocurrido en nuestro país.

[G6.70] Aunque haya gente que no esté de acuerdo porque puede que represente la victoria del franquismo, es parte de nuestra historia y todo el mundo debería de saberlo.

De esta manera, al "ser parte de la Historia", cualquier acontecimiento, resto material o elemento simbólico procedente del pasado toma un valor intrínseco, al considerarse como algo que debe conservarse. Estas reflexiones no asumen necesariamente una capacidad transformativa, como en el modelo crítico, ni tampoco tratan de contextualizar el porqué de la presencia de estos símbolos en un marco de cambio continuo, limitándose a observar la realidad existente, sin establecer ningún cuestionamiento.

\section{b. Una interpretación que marca la orientación}

El elemento clave del modelo tradicional de conciencia histórica es la interpretación que se hace del pasado, descrito como condicionante de las obligaciones en el presente. En este sentido, se concibe como necesaria la conservación de los restos del pasado pese a cualquier tipo de impedimento, ya sea de tipo moral o estético.

[G2.19] No quitaría los monumentos que hay referentes al Franquismo o a la victoria del Franquismo, porque es historia de nuestro país y aunque nos parezca bueno o malo tenemos que respetarla.

[G2.20] No hay que tirarlo porque es Historia Real y no se puede ocultar o eliminar, aunque quede feo tiene que ser así.

Esta concepción acerca del pasado, de tipo interpretativo, condiciona la actuación en el presente, es decir, la orientación. Es aquí cuando el mantenimiento de la tradición asume un papel fundamental, ya que es la conclusión lógica y práctica del proceso que interpreta el pasado para imaginar un nuevo futuro. Respondiendo a la pregunta de qué hacer con el conjunto monumental, la respuesta mayoritaria es, por tanto, el mantenimiento del mismo:

[G1.11] Si el hecho de mover en este monumento, estuviese en nuestras manos, decidiríamos dejarlo tal y como está en la actualidad.

[G4.44] Tendrían que dejarlo como esta, porque aunque es un símbolo franquista no molesta a nadie además también es una zona turística. 


\section{c. Aspectos morales}

La idea de conciencia moral, ligada desde diferentes tradiciones a los modelos de conciencia histórica (Körber, 2017; Rüsen, 2004), también ofrece un resquicio desde el que identificar las características propias de cada una de las diferentes visiones. En el caso de la aquí analizada, se observa cómo se asumen rasgos propios del marco moral tradicional, valorando los procesos del pasado desde este punto de vista para reforzar la opción por la que se decantan los autores de las respuestas.

[G2.23] Le mantendríamos ya que pertenece a la historia de España y porque quizás sin la política y la ideología que hubo, España no sería igual que es ahora. Y también es una manera de recordar porque [sic] ahora nuestro país es así y por lo que pasaron las personas que lo vivieron.

[G3.24] A ver, en mi opinión debería de quedarse ahí por que [sic] es parte de la historia y al que no le guste que no mire. Franco ganó y aunque quieran olvidarlo es parte de nuestro pasado y siempre habrá cosas como estas que nos lo recuerden y aunque no estén siempre sabremos a la perfección lo que paso.

Esto provoca que, aunque se valore el papel de las víctimas y sus familias, prima ante todo la idea de lo que "debe hacerse", sobreponiendo el peso de lo histórico y de la tradición ante cualquier reinterpretación, recontextualización o cambio radical, siempre observadas con reticencia. Esto, combinado con visiones más ligadas al esencialismo y que intuyen una preexistencia de identidades que perviven de forma continuista en el tiempo, provocan enfoques más categóricos, minoritarios, pero que indican la existencia de estrechos lazos en la concepción de las relaciones pasado-presente.

[G4.45] [...] me parece que no es malo estar enterrado en un sitio que significa tanto bien en España aunque tenga algo malo.

[G6.70] El franquismo no sólo trajo cosas negativas. Me parece que esto es algo muy importante para conservar, aunque haya gente que no quiera aceptarlo, pero si no quieren aceptar la historia de nuestro país no son españoles de verdad.

\subsection{Visión ejemplar}

El modelo de conciencia histórica ejemplar, cuyos rasgos identificadores pueden observarse en la Tabla 4, tiene como núcleo una concepción del pasado capaz de informar al presente sobre las actuaciones futuras. La Historia, desde este punto de vista, sirve como guía y en ocasiones como modelo, pero también como un espejo desde el que encontrar advertencias y descubrir errores para evitarlos en el futuro.

\section{Tabla 4}

Rasgos identificadores del modelo ejemplar atendiendo a la experiencia, interpretación, orientación y moralidad, de acuerdo con la caracterización de Rüsen (2005)

Rasgos identificadores del modelo ejemplar

Experiencia: generalización sobre reglas de conducta a seguir.

Interpretación: el pasado como una lección para el presente.

Orientación: aplicación de reglas derivadas del pasado.

Moralidad: reconocimiento según principios morales generales.

Fuente: elaboración propia a partir de Rüssen (2005). 
En el caso aquí analizado, centrado en la problemática del Valle de los Caídos, los participantes ofrecen respuestas en las que pueden adivinarse aproximaciones variadas en la que, a pesar de todo, predomina la tendencia a conservar en lo esencial el conjunto monumental. Ahora bien, la visión ejemplar se aleja de la tradicional al centrar su atención en reglas ideales, donde el contexto deja de tener una importancia tan central, y donde el pasado, el presente y el futuro se engarzan en una red dominada mucho más por la búsqueda de patrones de actuación. Entendiendo esta concepción, es posible analizar las respuestas desde un ángulo diferente al del modelo de conciencia tradicional, aunque la solución planteada no varíe multitud de ocasiones, de forma efectiva, a la preferida por el grupo anterior.

\section{a. La lección como eje de la interpretación y la orientación}

La visión del pasado queda marcada, tal y como puede detectarse en las respuestas categorizadas en este modelo, por la búsqueda de ejemplos a seguir, siempre desde el punto de vista del presente. De esta manera, se detecta una utilidad real, de cuyo aprovechamiento depende una correcta orientación hacia el futuro, sobre todo a la hora de tener conocimiento sobre lo que ocurrió.

[G5.57] Lo dejaría tal y como está, y trataría de conservarlo lo mejor posible, ya que las generaciones futuras también querrán saber lo que pasó antiguamente en su país, y monumentos como este les ayudarán bastante.

[G6.73] Mi opinión breve es que el Valle de los Caídos no debería ser retirado, ya que forma parte de la Historia de España, y ese episodio oscuro no puede ser olvidado.

El conocer lo que ocurrió para no repetir este "episodio oscuro" no se liga únicamente con el mero recuerdo con la información a proporcionar a "generaciones futuras", sino que toma forma como utilidad práctica, concretamente para no repetir aquello que se percibe como negativo o como no ideal.

[G1.05] Si nosotros fuéramos los encargados de este monumento, lo dejaríamos tal y como está, puesto que es parte de nuestra historia y, aunque a algunas personas les pueda molestar, es necesario recordar lo que ocurrió, ya que, el pueblo que no conoce su historia, está obligado a repetirla.

[G5.48] Moverlos a un museo del franquismo o dejarlos donde están porque es historia de España, por lo dolorosa que sea para algunos, como la colonización de lberia por Roma o la colonización de América por los españoles, son parte de la historia del país y cada vez que vea alguien algo relacionado con el franquismo sepa que España pasó por una dictadura y que si no mantenemos esta democracia podríamos volver a repetir la historia.

En respuestas como esta última, es posible observar que no todas las propuestas categorizadas como ejemplares asumen la idea de mantener el carácter de los restos franquistas, ya que se combinan ideas que toman rasgos propios de la visión genealógica, en la que la contextualización asume un papel clave.

En todo caso, la orientación hacia el futuro queda implícita en varias de las respuestas ofrecidas por los participantes, ya que se da por hecho que el conocimiento acerca del pasado será lo que permita discriminar los mejores métodos de actuación desde el presente. En tal caso, el conocimiento histórico deja de ser mera información para convertirse, como ya se ha indicado, y como puede verse en el ejemplo inferior, en un instrumento capaz de proporcionar reglas y lecciones que únicamente deben ser aplicadas. 
[G5.57] Lo dejaría tal y como está, y trataría de conservarlo lo mejor posible, ya que las generaciones futuras también querrán saber lo que pasó antiguamente en su país, y monumentos como este les ayudarán bastante.

\section{b. ¿Por qué mantener el conjunto monumental?}

Aunque la mayoría de las respuestas encuadradas en la visión ejemplar son partidarias de mantener el Valle de los Caídos tal y como existe en la actualidad, lo cierto es que se observan discrepancias, a diferencia de las contestaciones ligadas al modelo tradicional, donde puede detectarse unanimidad. En esta ocasión, 19 de las 26 soluciones propuestas están de acuerdo en mantener el conjunto monumental, mientras que dos de ellas relacionan este proceso con la eliminación de los restos de los protagonistas políticos. Cinco respuestas hacen hincapié, por otro lado, en la necesidad de un proceso de reforma en profundidad, mediante la eliminación de símbolos o transformaciones en su uso. A pesar de esta pluralidad parcial de visiones detectada, los argumentos y razones presentadas despiertan interés, especialmente para establecer una diferenciación frente a otro tipo de visiones, por lo que se ha analizado este aspecto de forma particular.

Además de razonar que el conjunto forma parte de la Historia del país, algo a lo que ya se ha hecho referencia con anterioridad, una parte significativa de los argumentos (presentes en siete textos) giran en torno a la concepción del Valle de los Caídos como una obra de arte o monumental, y por tanto, como un resto cultural ligado a la expresión artística nacional.

[G2.22] Nosotras pensamos que este monumento debería ser conservado, ya que es parte de nuestra historia y nuestro patrimonio, y están enterradas personas de ambos bandos, de los vencedores y los perdedores, por eso deberíamos mantenerlo aunque no nos agrade la idea, y conservar todo lo que hay en él, sin trasladarlo, y ser posible visitarlo para conocerlo y conocer nuestra cultura.

[G3.27] Aunque para cierta gente no sea de agrado verlo, se tiene que respetar, ya que es un monumento importante y de hecho Patrimonio Nacional.

Este argumento se liga en ocasiones al turismo, o a aspectos económicos (en un total de seis respuestas diferentes), expresando el hecho de que, para una parte importante de los participantes adscritos a este modelo de conciencia histórica, los aspectos ideológicos no suelen predominar necesariamente frente a los prácticos, mucho más tendentes a buscar una solución pragmática o que ofrezca beneficios.

[G3.26] Al ser Patrimonio Nacional y además un monumento histórico, muchos turistas van a visitarlo y entonces si lo destruimos haríamos que empeorara la economía en España.

Pese a centrarse en ocasiones en elementos materiales, las respuestas encuadradas en esta visión no tienden a advertir el carácter simbólico del monumento (algo que sí ocurre con frecuencia en el modelo crítico de conciencia, como se verá más adelante), salvo el caso que se presenta a continuación, capaz de identificar la dualidad entre el monumento como tal y lo que representa.

[G3.27] Por otra parte, puede que mucha gente, al representar la victoria franquista, vean despreciable que se mantenga aún ese monumento allí, ya que a otros países del mundo puede que les de [sic] sensación que [sic] España está orgulloso [sic] de ese 
monumento y por qué [sic] se construyó.

En todo caso, esta falta de apreciación provoca que varios de los participantes puedan caer en el uso de razonamientos más vagos, donde además no se diferencia claramente entre el pasado, la Historia y su uso en el presente.

[G2.17] Yo lo que haría con este monumento es dejarlo donde esta [sic], ya que forma parte de España y yo creo que no hace daño a nadie y tampoco puedes cambiar la historia solo con quitar monumentos, símbolos, etc.

[G5.49] [...] lo dejaría como está ya que cambiar algo supondría un debate que puede reabrir heridas del pasado.

\section{c. Limitaciones e incapacidad de actuación}

Precisamente, y en relación con este último aspecto, es interesante entender uno de los elementos centrales del modelo ejemplar de conciencia histórica: la dificultad de integrar ideas críticas o rupturistas en los modelos establecidos. Como se ha apuntado con anterioridad, existen propuestas de reforma dentro de las respuestas analizadas, pero además de ser muy inferiores en número, suelen limitarse a la creación de museos (en un total de cuatro ocasiones). En relación a los aspectos ligados a la moralidad, existe una preocupación por el reconocimiento a las víctimas y sus familias (presente en alrededor de la mitad de los textos), y a diferencia del modelo crítico, más centrado en el reconocimiento al bando republicano, aquí se observa una tendencia a tratar de superar el conflicto de bandos,

[G6.73] De todas formas, me gustaría que se pusiera una placa o una leyenda en la cual se plasmara cómo en este monumento no están honrados los franquistas o los republicanos, sino los que murieron por una España mejor.

En todo caso, y volviendo a la concepción de las posibilidades de actuación y orientación de cara al futuro, el modelo ejemplar deja muestras de mirar con reverencia al pasado: no en el sentido de la visión tradicional analizada con anterioridad, sino en un sentido que casi roza el determinismo, como puede observarse en ciertas respuestas.

[G5.62] Hay que conservar el Valle de los Caídos, porque es importante respetar la historia. Los hechos sucedieron de una forma y no de otra nos guste o no. Es como si un científico obtiene un resultado en un experimento que no es el que esperaba, con objetividad debe aceptar ese resultado y no falsificarlo o manipularlo. Las victorias y las derrotas, los hechos históricos quedan reflejados en variedad de fuentes, algunas materiales. No estamos legitimados para destruir esas fuentes o modificarlas a nuestro antojo.

\subsection{Visión crítica}

La concepción de la legitimación a la hora de enfrentarse al pasado queda resuelta en el modelo crítico de conciencia histórica de una forma muy directa: los hechos o procesos ya acontecidos no tienen por qué ser unos grilletes que limiten o condicionen la acción del presente. De igual forma, el futuro queda por decidir, por lo que cualquier adaptación a principios preexistentes se debe exclusivamente a la decisión autónoma de los agentes que construyen la Historia, y no al seguimiento ciego de reglas procedentes del pasado (Tabla 5). 
Tabla 5

Rasgos identificadores del modelo crítico atendiendo a la experiencia, interpretación, orientación y moralidad, de acuerdo con la caracterización de Rüsen (2005) \begin{tabular}{l}
\hline Rasgos identificadores del modelo crítico \\
\hline Experiencia: examen del pasado siempre desde el presente. \\
Interpretación: enfrentamiento a los marcos heredados. \\
Orientación: refutación y creación de nuevos valores. \\
Moralidad: reconocimiento según principios morales propios. \\
Fuente: elaboración propia a partir de Rüssen (2005).
\end{tabular}

De forma concreta, y en el contexto derivado de la tarea encargada a los participantes, es incorrecto suponer que una visión considerada como crítica supone de forma automática una ruptura de todos los marcos existentes, y por tanto, una defensa de la desaparición del conjunto monumental. Es importante recalcar que los modelos de conciencia histórica descritos no se relacionan con la ideología política, sino con las concepciones en torno al lugar propio dentro de los procesos de cambio histórico y sobre la relación entre el pasado, el presente y el futuro, razón por la que participantes con propuestas muy diferentes puedan compartir los rasgos centrales de cada tipología.

Concretamente, y aunque 12 de las 20 respuestas obtenidas están a favor de soluciones que pasan por la eliminación del Valle de los Caídos, tres textos defienden el mantenimiento del monumento y cinco proponen reformas concretas, incluyendo la contextualización o historización del complejo. En todo caso, y de forma transversal, se habla de la necesidad de centrar la atención en los símbolos todavía existentes.

\section{a. La preocupación por la simbología}

Frente a los participantes encuadrados en otras visiones, los relacionados con la crítica asumen de forma mayoritaria el significado del monumento y de los otros restos de la etapa franquista, siendo conscientes de lo que representan. De esta forma, la construcción histórica y su simbología no se ven como dadas o ajenas, sino como artificiales, y por eso mismo capaces de ser modificadas.

[G2.16] Hay que quitarlo porque es un símbolo de una dictadura donde España paso por un periodo de opresión, persecución a los que tenían distintas opiniones.

[G3.31] En mi opinión, ya que este "monumento" es una oda al régimen, debería de desaparecer con el tiempo, pues es un símbolo que ata al país con su oscuro y vergonzoso pasado.

La idea de un pasado vergonzoso provoca una identificación, entre muchos de los participantes, de la mera existencia del conjunto monumental con lo que representó en el momento de su construcción, aunque no aparecen reflejadas ideas ligadas con el proceso de recontextualización producido a lo largo del tiempo, y de los cambios de sentido y significado llevados a cabo en las últimas décadas. De esta manera, en muchas de las respuestas no se perciben los matices que sí serán encontrados posteriormente, en el análisis del modelo genealógico de conciencia histórica.

[G3.29] Deberíamos destruir todos aquellos monumentos franquistas, ya que nos avergüenzan por su origen y por todo a lo que nos ha llevado, aunque no deberíamos olvidar lo que pasó para no repetirlo. Que aún se conserven monumentos y calles es algo vergonzoso y demuestra que muchos se enorgullecen de aquellas matanzas e 


\section{injurias provocadas por la dictadura.}

Por otro lado, la identificación de los significados simbólicos hace que no escape a la atención de algunos de los participantes la relación de España con su contexto, provocando que se produzca una comparación con otros países, como Italia o Alemania (dos referencias), donde también se implantaron regímenes autoritarios, criticando el mantenimiento de usos específicos del pasado en el caso español.

[G1.09] Es entendible que forme parte de la historia de España, pero no veo a ningún alemán yendo a ningún cementerio a rezarle al cuerpo de Hitler.

\section{b. Una interpretación crítica para orientarse desde el presente}

Una de las características de la visión crítica tiene que ver con su capacidad para ver los procesos del pasado con los valores del presente. Si, por un lado, esto tiene el riesgo de favorecer el presentismo, descartando una mirada informada por la perspectiva histórica y la contextualización, por el otro, es capaz de promover nociones transformadoras.

[G3.31] Deberíamos de dejar de mirar al pasado, que no nos va a decir nada nuevo, y observar al futuro, despojándonos de las cadenas que nos atan a ese tiempo.

Concepciones de este estilo pueden quedar limitadas a la interpretación de los acontecimientos históricos, pero tienen el potencial de asumir un carácter práctico. Es aquí cuando la interpretación informa a la orientación, ya que si la experiencia de este modo de conciencia histórica es una continua interpelación a los marcos establecidos desde el pasado, la refutación y ruptura es su expresión práctica.

Sería engañoso, a pesar de todo, suponer que una totalidad de las respuestas obtenidas llegan a confrontar de forma directa el contorno en el que se mueven, y de ahí la importancia de entender la existencia de graduaciones y enfoques. Por un lado, como puede observarse a continuación, se detecta una tendencia a querer actuar contra el statu quo, y por tanto a transformar radicalmente la realidad mediante la destrucción de los símbolos del mundo que se quiere superar, sin tener en cuenta más aspectos que los significados inicialmente otorgados en su génesis.

[G6.69] En otros casos, como placas o estatuas, veo bien que se retiren y se guarden en otro sitio, pero en este caso creo que se debería destruir por completo. Este monumento es el más polémico de todos los símbolos franquistas, y por ello debería ser desmantelado.

Por supuesto, la orientación basada en la refutación del pasado también puede orientarse hacia otro tipo de soluciones, especialmente cuando, tal y como se ha apuntado en la sección anterior, aquellas personas encuadradas en este tipo de visión son capaces de reinterpretar el pasado y su simbología a través de sus propios valores, que sobreponen a los existentes.

[G3.35] Yo creo que haríamos mal en destruir o mover de su sitio un monumento histórico ya con un significado, ya que este monumento tiene como significado, la utilización de esclavos republicanos para crear este monumento, ese es el significado que da la gente para que lo destruyan, pero yo creo que ese no es el significado, para mi [sic] el significado es que no hay que crear una guerra para que se haga lo que quiera alguien si no [sic] exponerlo e intentar de otros medios conseguir el sistema político que quieras.

[G4.39] [Se debería] cambiar su significado, por ejemplo llamarlo de otro nombre 
o que simbolice a otras personas porque no creo que sean dignos de un monumento.

Como se advierte al analizar los textos, las percepciones sobre el periodo, plagadas, en algunos casos, de inexactitudes (por ejemplo, al hablar de esclavitud), marcan claramente la orientación a tomar. Asimismo, otras respuestas centran su atención en propuestas de musealización o contextualización, aunque son mucho más escasas que en el modelo genealógico de conciencia. En el caso del modelo crítico, pueden observarse diferentes propuestas, más o menos difíciles de llevar a la práctica, pero generalmente ausentes en otro tipo de visiones.

[G5.60] Quitaríamos los restos del dictador Francisco Franco ya que el Valle de los Caídos representa aquellos que murieron en la Guerra Civil. Mientras que él no falleció en combate. Además el [sic] fue el causante de todos estos muertos, por lo cual mantener sus restos allí, sería una ofensa hacia los familiares de los fallecidos en este enfrentamiento bélico.

[G3.30] No opino que se deban destruir, sino mover a un lugar donde las personas que quieran verlas puedan. Respecto a las calles o institutos/colegios con nombres franquistas deberían cambiar el nombre de estos. Si hablamos del Valle De Los Caídos, seria [sic] algo mas [sic] difícil de plantear, ya que un monumento tan grande seria [sic] muy difícil de mover. Desde mi punto de vista, yo creo que se debería dejar a las familias mover los cuerpos de su familia de ahí, si ellos desean.

\section{c. Reivindicación y reconocimiento como eje moral}

Precisamente, y en relación con el reconocimiento a las víctimas y a sus familiares propugnada por los dos últimos ejemplos, las respuestas muestran, de una forma general, una preocupación por valorar el papel de las víctimas de la Guerra Civil y de la etapa franquista. Pese a que este elemento también está presente en el resto de visiones analizadas, el modelo crítico se diferencia al no caer en la equidistancia detectada en otros casos y en hacer muy explícito el reconocimiento a los represaliados o a las víctimas republicanas. Este aspecto, ya percibido como parte de las respuestas correspondientes a la visión ejemplar, se hace aquí más presente, aunque sean mayoritarias las referencias a las víctimas de ambos bandos.

[G1.02] Yo creo que por lo menos la cruz la deberían de quitar, y si no la quitaran, poner lápidas en reconocimiento a los republicanos que murieron construyendo este monumento.

[G6.68] [...] dudo mucho que familiares de las víctimas del bando republicano quieran tener los restos de sus familias enterrados en un sitio así.

El carácter reivindicativo no es el único encontrado en los textos, ya que la visión crítica tiene entre sus rasgos la orientación moral según criterios propios, y de ahí que no sea tan extraño el que se rechace el conflicto de forma global, sin tratar de establecer una identificación con uno de los dos bandos.

[G3.28] No es de estar orgullosos de una guerra civil. Para simbolizar estas muertes creo que es suficiente dejando la cruz y el recuerdo en libros de historia o en las mentes de los mas [sic] ancianos que vivieron la época [sic].

No todas las respuestas analizadas correspondientes a este modelo de conciencia histórica asumen como eje central la reivindicación y el recuerdo a las víctimas republicanas, sino que muchos de los textos prefieren hacer hincapié en cuestiones más prácticas, como los aspectos económicos. 
[G6.65] Yo personalmente lo haría desaparecer, no sólo porque representa de alguna forma la victoria del régimen franquista, sino también porque el dinero utilizado para mantenerlo procede del estado, es decir de todos los ciudadanos.

[G6.71] ¿Y si esa gente en contra no quiere participar en el mantenimiento del monumento? ¿De veras tienen que estar obligados a pagar por algo que no quieren? por [sic] eso deberían derrumbarlo, porque como pertenece al Estado, todos los españoles tienen que pagar el mantenimiento del monumento, aunque sea en contra de su voluntad.

En todo caso, la existencia de estos últimos ejemplos es una indicación más de la variedad de expresiones que el modelo crítico de conciencia histórica puede asumir, donde los valores adoptados como prioritarios no tienen por qué responder a concepciones ideológicas concretas, pese a las predisposiciones ofrecidas por temáticas específicas.

\subsection{Visión genealógica}

Pese a observarse de forma significativamente menos frecuente que el resto de visiones, seis de los textos obtenidos son categorizados dentro de la visión genealógica, asumiendo sus características esenciales (Tabla 6). A diferencia de los otros modelos de conciencia histórica, más interesados en contemplar el pasado como un elemento frente al que definirse, ya sea mediante el abrazo de la tradición, la búsqueda de reglas inmutables, o el enfrentamiento ante lo establecido, la visión genealógica se ocupa más de la contextualización, interesándose por el origen de lo actualmente existente.

Tabla 6

Rasgos identificadores del modelo genealógico atendiendo a la experiencia, interpretación, orientación y moralidad, de acuerdo con la caracterización de Rüsen (2005)

Rasgos identificadores del modelo genealógico

Experiencia: evolución, adaptación y transformación en el tiempo.

Interpretación: contextualización de los procesos históricos y actuales.

Orientación: adaptación dinámica a las transformaciones.

Moralidad: concienciación de la naturaleza dinámica y adaptativa.

Fuente: elaboración propia a partir de Rüssen (2005).

Entendida la concepción esencial de este modelo de conciencia histórica, no es de extrañar que las soluciones propuestas pasen siempre por el proceso de contextualización o historización del conjunto monumental, al entenderlo como una expresión histórico-cultural concreta localizada en el tiempo. Por supuesto, la valoración del monumento como un producto de su época no significa que se convierta en un elemento a analizar acríticamente, puesto que los participantes entienden que junto al proceso de conservación pueden aportarse soluciones que pasen por la reforma del complejo o la retirada de restos, como puede verse en los ejemplos seleccionados más adelante.

\section{a. Una manera diferente de enfrentarse al pasado}

La interpretación del modelo genealógico asume la necesidad de conocer los contextos, y por tanto, los orígenes que dieron lugar a la existencia de los restos del pasado en el presente. Desde este punto de vista, comprender y analizar los procesos históricos se asume como algo importante, pero no con el objetivo de imitarlos (como en el caso de la visión tradicional), sino más bien para simplemente entenderlos. 
[G5.56] Lo dejaría como un monumento para los caídos en la guerra y una especie de museo en el que explicaran como [sic] fue la guerra civil y las repercusiones que trajo.

[G3.36] En este monumento lo correcto en opinión sería la creación de un museo con todos los elementos característicos y polémicos que forman parte del franquismo, con un museo los elementos franquistas no tendrían que estar en la calle, pero aun así se podría seguir estudiándolos en un museo donde se puede aprender sobre la historia de España.

Como apunta esta última respuesta, el hecho de querer comprender el pasado lleva, de forma general, a proponer como solución una musealización que ponga en contexto lo acontecido. La razón por la que no se producen propuestas que supongan la desaparición del conjunto tiene que ver con la orientación mostrada por este tipo de visiones, donde se perciben pequeños atisbos de comprensión acerca del factor dinámico de los procesos temporales y los constantes juegos de contextualizaciones y recontextualizaciones según épocas.

Pese a esto, el hincapié hecho por los distintos participantes no siempre se centra en el propio proceso de historización, ya que muchas de las respuestas combinan elementos propios de otros modelos, como el crítico, dando especial relevancia al simbolismo y siendo exigentes en lo relativo al reconocimiento de las víctimas.

[G6.67] Desde mi punto de vista habría que replantear el conjunto, su función y su simbolismo por completo. No es para nada justo su planteamiento actual, que ensalza el mérito y la memoria de aquellos que se alzaron contra una democracia del pueblo con las armas y con la muerte, mientras que los huesos de los que defendieron dicha democracia se pudren en las cunetas, sin nombre ni dignidad. La cuestión sería, por tanto, lograr un sitio de interpretación del régimen dictatorial franquista y de la Guerra Civil, desde un punto de vista neutral e igualitario, para que todo el mundo se sintiera representado en dicho espacio.

La solución ofrecida posteriormente por este participante es la "creación de un centro de interpretación del conjunto", con el objetivo de conocer en profundidad los acontecimientos para lograr la reconciliación, pero también incluye propuestas que se ligan a, como se ha indicado, visiones críticas, donde pesa mucho la eliminación de la simbología, y donde se produce una actuación más activa.

[G6.67] Exhumación de Franco y de José Antonio Primo de Rivera y retirada de sus cuerpos. Cerrar la Iglesia del Valle de los Caídos: para retirar la conexión que la Iglesia tuvo con la dictadura y el nacionalcatolicismo.

En todo caso, la utilización del museo como arma para dotar de nuevos significados a los espacios preexistentes se repite en casi todas las ocasiones, con mayores o menores matices, aunque siempre en contextos marcados por soluciones diversas, en las que se mantiene o se reforma el conjunto monumental.

[G5.50] Creo que el monumento debería dejarse tal y como está, en caso de pequeñas estatuas y otros símbolos franquistas como pueden ser placas con nombres relacionados con el franquismo para calles podrían ser retirados y llevados a museos pero el Valle de los Caídos podría ser incluso considerado como museo por su tamaño y su importancia histórica.

[G2.18] Lo convertirla en un museo donde se alberguen demás símbolos franquistas para no dañar los sentimientos e ideas de aquellas personas que padecieron este momento de la historia de España. 
Pese a los limitados ejemplos de textos ligados a este modelo de conciencia histórica, mucho menos numerosos que en otras visiones, queda patente la idea de que cualquier tipo de proceso derivado del pasado y su continua reinterpretación se observa con una cierta naturalidad. Esto provoca que, a pesar de que se identifiquen las funciones de los restos históricos como influyentes y con capacidad de simbolización en el presente, o que las convicciones personales lleven a sugerir reformas o transformaciones de calado, éstas siempre queden subordinadas a la comprensión y a la conservación de los elementos esenciales procedentes de épocas pasadas.

\section{Discusión y conclusiones}

La experiencia llevada a cabo en los diferentes centros educativos en torno a los restos de la etapa franquista, así como el análisis de las respuestas proporcionadas por los estudiantes, han permitido observar varios aspectos de interés ligados, no solamente con las apreciaciones o concepciones más profundas del alumnado sobre parte de la Historia reciente, sino también relacionados con el marco utilizado para la investigación, centrado en el concepto de conciencia histórica.

\subsection{La conciencia histórica y sus distintos modelos}

En primer lugar, e independientemente de la distribución encontrada en los distintos grupos, es importante indicar que la discriminación entre las diferentes categorías siguiendo la tipología presentada por Rüsen (2005) ha facilitado el examen de la información obtenida, confirmando, mediante la codificación utilizada, los rasgos característicos de cada una de las visiones. Por supuesto, tal y como se ha indicado desde la propia conceptualización teórica de los modelos de conciencia histórica, "de forma habitual, los diferentes tipos aparecen en mezclas complejas" (Rüsen, 2004, p. 81), algo que ha podido corroborarse en esta investigación ya que, si bien muchas de las respuestas muestran un sentido completamente coherente, en varias de ellas han podido observarse una serie de combinaciones de rasgos diversos, como se ha advertido al examinar algunos de los ejemplos.

A lo largo del proceso de análisis de los resultados procedentes de esta investigación ha quedado patente la existencia de visiones muy marcadas, con un sentido de la interpretación y de la orientación condicionado por preferencias diversas. En primer lugar, destacan las continuas llamadas, observadas primordialmente en los modelos tradicional y ejemplar, al reconocimiento de cualquier vestigio del pasado como parte de la Historia, argumento central en multitud de las respuestas analizadas a la hora de defender el mantenimiento de los restos de la etapa franquista. Cada una con sus propios rasgos, tanto la visión tradicional (en la que el mantenimiento de lo heredado asume un papel central) como especialmente la ejemplar (donde se buscan lecciones y modelos a imitar) son mayoritarias en el contexto analizado, aunque las diferencias detectadas entre ambas, a pesar de coincidir en algunas de las soluciones propuestas, sean las que acaparan el mayor interés del estudio.

El modelo crítico de conciencia histórica, a pesar de no ser mayoritario, asume un peso relevante, aunque merezca la pena recordar que los enfoques, especialmente los agrupados ante este tipo de visión, son muy variados, así como las soluciones propuestas. En este caso destaca, tal y como ha sido señalado, la identificación y preocupación por la simbolización y los significados, algo no habitualmente presente en otras visiones. Por último, es importante destacar la escasa presencia del modelo genealógico, minoritario en este caso, pero claramente atraído por la historización y por un tipo de visión en el que cualquier transformación trata de ponerse en su contexto, sin renegar, pese a todo, de la actuación en el presente según criterios propios.

Las categorías tradicional, ejemplar, crítica y genealógica han resultado, por tanto, útiles, mostrando diferencias de calado en los enfoques y expresiones de la conciencia histórica proporcionadas por los participantes en la investigación, incluso en los aspectos relacionados con 
la moralidad (Körber, 2017). En esta ocasión, pese a seguir el modelo de investigación realizado por Seixas y Clark en torno a los murales de Canadá, no se ha intentado establecer una relación entre las categorías elaboradas por Nietzsche sobre la aproximación a la Historia (visiones monumental, anticuaria, crítica y moderna) y las propuestas por Rüsen, aunque probablemente no hubiera resultado complejo, teniendo en cuenta el esfuerzo de relación teórica establecido por los autores (Seixas y Clark, 2004).

\subsection{Comparativa ante experiencias previas}

Precisamente, y en segundo lugar, merece la pena establecer una comparación de los resultados obtenidos con los procedentes de experiencias previas citadas con anterioridad, y focalizadas en el trabajo en torno al patrimonio, aunque siempre advirtiendo que el contraste entre los contextos provoca que la comparativa sea meramente orientativa.

El trabajo realizado en Portugal en torno a las concepciones de estudiantes de Educación Secundaria sobre el uso de la evidencia de los lugares históricos indica que la mayor parte de los estudiantes únicamente tiende a entender el pasado como atemporal o con significados estáticos. En este sentido, en esa investigación se detectó como más frecuente la capacidad de simbolizar el pasado según visiones tradicionales (por ejemplo, a través de la idea de edad dorada) o ejemplares, siendo mucho más extrañas las visiones crítica y genealógica, al "exigir un mayor esfuerzo y un pensamiento más sofisticado por parte de alumnos y profesores" (Pinto, 2016, p. 335). Desde este punto de vista, los resultados coinciden en parte con este estudio, ya que la visión genealógica ha sido el modelo en el que menos participantes han quedado encuadrados.

Por otra parte, la visión crítica, más escasa en el estudio de Pinto, muestra aquí mayor presencia, probablemente debido a lo polémico o controvertido del proceso histórico seleccionado, un aspecto que, como se ha apuntado con anterioridad, puede forzarnos a observar los resultados con cierto cuidado. Es, desde este punto de vista, válido cuestionarse hasta qué punto un factor como la orientación política o ideológica puede afectar a las respuestas obtenidas, pero, sobre todo, de qué manera estos aspectos pueden llegar a convertirse en un condicionamiento más o menos fuerte al trabajar sobre procesos históricos determinados, especialmente los ligados a la Historia reciente.

Por último, en el caso de la comparación con el estudio de Seixas y Clark en la Columbia Británica, de las 57 respuestas analizadas, ninguna pudo ser encuadrada en la visión monumental de Nietzsche (específica, pero con algún rasgo de la tradicional de Rüsen), pero 18 lo hicieron en la anticuaria (correspondiente en parte a la ejemplar), 29 en la crítica y ocho en la moderna (correspondiente a la genealógica). Esta distribución, aunque determinada por la ausencia del modelo tradicional, queda marcada, al igual que esta investigación, por la polémica despertada por los murales. Tanto en esta como en aquella ocasión, al plantear al alumnado qué hacer con estos restos monumentales, muchos de ellos apuestan por visiones más rompedoras, como una forma de reivindicarse ante el marco del presente, sintiéndose, en el caso canadiense, "cómodos al juzgar los murales según la base de la carga moral que las imágenes traen al presente" (Seixas y Clark, 2004, p. 168). De nuevo, la visión genealógica, ligada a la contextualización, está presente, pero con mucho menor peso que las otras.

\subsection{Perspectivas de futuro y reflexiones finales}

Pese a las limitaciones de este estudio, centrado en el análisis de un proceso histórico controvertido muy concreto, y sobre el que los participantes tienen frecuentemente ideas preconcebidas, ya sea por la presencia de los debates en los medios de comunicación o en ámbitos familiares, no cabe duda de que la polémica es un aspecto que precisamente puede ayudar a identificar concepciones diversas. De esta manera, es posible justificar que el análisis de los modelos de conciencia histórica del alumnado puede ser enfocado a partir de la Historia más reciente, así 
como de los restos patrimoniales, aunque también pueda orientarse a través del examen identitario y de los procesos de construcción nacional (Angier, 2017; Lévesque et al., 2015).

De igual forma, y al entenderse como posible el establecimiento de lazos entre la caracterización de habilidades de pensamiento histórico y el concepto de conciencia histórica (Duquette, 2015; Körber, 2011), cualquier tipo de trabajo en torno a las competencias históricas puede hacer uso de las categorías ligadas con la conciencia. La doble dimensión, reflexiva y ligada con la orientación y la función de la Historia, y aquella relacionada estrechamente con el campo disciplinar, asumen por tanto un importante potencial para el trabajo en el aula.

En todo caso, y por último, cabe preguntarse hasta qué punto el alumnado es consciente de sus propias preferencias y concepciones más profundas, así como de los elementos y contextos particulares que les han predispuesto en una u otra dirección. Queda como labor del profesorado y de futuras investigaciones profundizar más en los modelos de conciencia histórica detectada en diferentes etapas, así como en la argumentación proporcionada por los estudiantes. El objetivo, después de todo, es identificar rasgos comunes con la meta de solventar dificultades de comprensión o aprendizaje, así como proponer formas de trabajar en torno a aspectos como la simbolización, o las transformaciones de los significados históricos mediante una reflexión propia basada en la explicitación de visiones.

\section{Bibliografía}

Ahonen, S. (2005). Historical Consciousness: A Viable Paradigm for History Education? Journal of Curriculum Studies, 37(6), 697-707. https://doi.org/10.1080/00220270500158681

Angier, K. (2017). In Search of Historical Consciousness : An Investigation into Young South Africans' Knowledge and Understanding of "Their» National Histories. London Review of Education, 15(2), 155-173. https://doi.org/10.18546/LRE.15.2.03

Bermúdez, Á. (2012). The Discursive Negotiation of Narratives and Identities in Learning History. En M. Carretero, M. Asensio, y M. Rodríguez-Moneo (Eds.), History Education and the Construction of National Identities (pp. 203-219). Charlotte: Information Age Publishing.

Chapman, A. (2014). «But it Might Not Just Be Their Political Views»: Using Jörn Rüsen's «Disciplinary Matrix» to Develop Understandings of Historical Interpretation. Cadernos de Pesquisa: Pensamento Educacional, 9(21), 67-85.

Corbin, J., y Strauss, A. (2008). Basics of Qualitative Research: Techniques and Procedures for Developing Grounded Theory (3. ${ }^{a}$ Ed.). Thousand Oaks: SAGE Publications.

Duquette, C. (2015). Relating Historical Consciousness to Historical Thinking Through Assessment. En K. Ercikan y P. Seixas (Eds.), New Directions in Assessing Historical Thinking (pp. 51-63). New York: Routledge.

Fuentes, C. (2004). Concepciones de los alumnos sobre la Historia. Enseñanza de las Ciencias Sociales. Revista de investigación de las Ciencias Sociales, 3, 75-83.

Gadamer, H.-G. (1975). The Problem of Historical Consciousness. Graduate Faculty Philosophy Journal, 5(1), 8-52.

Gay, L. R., Mills, G. E., y Airasian, P. (2012). Educational Research: Competencies for Analysis and Applications (10. ${ }^{\text {a }}$ Ed.). Boston: Pearson.

Jeismann, K.-E. (1997). Geschichtsbewußtsein - Theorie. En K. Bergmann, K. Fröhlich, A. Kuhn, J. Rüsen, y G. Schneider (Eds.), Handbuch der Geschichtsdidaktik (pp. 42-45). Düsseldorf: Kallmeyer.

Kölbl, C., y Konrad, L. (2015). Historical Consciousness in Germany: Concept, Implementation, Assessment. En K. Ercikan y P. Seixas (Eds.), New Directions in Assessing Historical Thinking (pp. 17-28). New York: Routledge.

Körber, A. (2011). German History Didactics: From Historical Consciousness to Historical Competencies - and Beyond? En H. Bjerg, C. Lenz, y E. Thorstensen (Eds.), Historicizing the Uses of the Past: Scandinavian Perspectives on History Culture, Historical Consciousness 
and Didactics of History Related to World War II (pp. 145-164). New Brunswick: Transaction Publishers.

Körber, A. (2017). Historical Consciousness and the Moral Dimension. Historical Encounters: $A$ journal of historical consciousness, historical cultures, and history education, 4(1), 81-89.

Koselleck, R. (2004). Futures Past. On the Semantics of Historical Time. New York: Columbia University Press.

Lee, P. J. (2002). «Walking Backwards into Tomorrow». Historical Consciousness and Understanding History. International Journal of Historical Learning Teaching and Research, 4(1), 69-114.

Lévesque, S., Croteau, J. P., y Gani, R. (2015). Conscience historique des jeunes francophones d'Ottawa: sentiment d'appartenance franco-ontarienne et récit du passé. Revue du NouvelOntario, 27(40), 177. https://doi.org/10.7202/1032587ar

López, C., Carretero, M., y Rodríguez-Moneo, M. (2014). Fostering National Identity, Hindering Historical Understanding. En K. R. Cabell y J. Valsiner (Eds.), The Catalyzing Mind: Beyond Models of Causality (pp. 211-221). New York: Springer. https://doi.org/10.1007/978-1-46148821-7 11

Lowenthal, D. (1998). The Heritage Crusade and the Spoils of History. Cambridge: Cambridge University Press.

Miguel-Revilla, D., Carril, T., y Sánchez-Agustí, M. (2017). Accediendo al pasado: creencias epistémicas acerca de la Historia en futuros profesores de Ciencias Sociales. REIDICS. Revista de Investigación en Didáctica de las Ciencias Sociales, 1, 86-101. https://doi. org/10.17398/2531-0968.01.86

Nora, P. (1989). Between Memory and History: Les Lieux de Mémoire. Representations, 26, 7-24. https://doi.org/10.2307/2928520

Parra, D. (2017). Educación histórica e identidad nacional. Íber. Didáctica de las Ciencias Sociales, Geografía e Historia, 89, 7-11.

Pinto, H. (2016). Educação Histórica e Patrimonial: conceções de alunos e professores sobre o passado em espaços do presente. Porto: CITCEM.

Ricoeur, P. (2004). Memory, History, Forgetting. Chicago: The University of Chicago Press.

Rüsen, J. (2001). What is Historical Consciousness? A Theoretical Approach to Empirical Evidence. En Canadian Historical Consciousness in an International Context: Theoretical Frameworks. Vancouver: Centre For The Study of Historical Consciousness (University of British Columbia).

Rüsen, J. (2004). Historical Consciousness: Narrative, Structure, Moral Function and Ontogenetic Development. En P. Seixas (Ed.), Theorizing Historical Consciousness (pp. 63-85). Toronto: University of Toronto Press.

Rüsen, J. (2005). History: Narration, Interpretation, Orientation. New York: Berghahn Books.

Santisteban Fernández, A. (2017). Del tiempo histórico a la conciencia histórica: cambios en la enseñanza y el aprendizaje de la historia en los últimos 25 años. Diálogo Andino, 53, 87-99. https://doi.org/10.4067/S0719-26812017000200087

Seixas, P. (Ed.). (2004). Theorizing Historical Consciousness. Toronto: University of Toronto Press.

Seixas, P., y Clark, P. (2004). Murals as Monuments: Students' Ideas about Depictions of Civilization in British Columbia. American Journal of Education, 110(2), 146-171. https://doi. org/10.1086/380573

Seixas, P., y Morton, T. (2013). The Big Six Historical Thinking Concepts. Toronto: Nelson.

Stake, R. E. (2010). Qualitative Research. Studying How Things Work. New York: The Guilford Press.

Traverso, E. (2007). Historia y memoria. Notas sobre un debate. En M. Franco y F. Levín (Eds.), Historia reciente. Perspectivas y desafíos para un campo en construcción (pp. 67-96). Buenos Aires: Paidós.

VanSledright, B. A., y Maggioni, L. (2016). Epistemic Cognition in History. En J. A. Greene, W. A. Sandoval, y I. Bråten (Eds.), Handbook of Epistemic Cognition (pp. 128-146). New York: Routledge. 


\section{Panta Rei}

PANTA REI es una revista digital de investigación orientada a la Historia y otras ciencias afines. Su principal objetivo es la transmisión del conocimiento científico, dando una oportunidad también a los jóvenes investigadores que quieren abrirse camino en el estudio de las ciencias humanas y sociales. Se compone de estudios originales relacionados con la disciplina histórica así como su didáctica y difusión. Las diferentes secciones que componen la revista son: artículos de investigación, entrevistas a profesionales, recensiones de monografías de actualidad y crónicas de congresos o eventos científicos relevantes.

Todos los artículos publicados son objeto de un proceso de revisión a cargo de un mínimo de dos evaluadores, que se consideran expertos en el ámbito temático del artículo propuesto. Nuestro deseo es poder ofrecer unos contenidos rigurosos, de calidad y de interés.

EI CEPOAT (Centro de Estudios del Próximo Oriente y la Antigüedad Tardía de la Universidad de Murcia) es la institución encargada de la coordinación y gestión de la revista, desde donde anualmente se lanzará la convocatoria para aquellos que estén interesados en publicar sus trabajos, siempre relacionados con la Historia, Arqueología, Historia del Arte, Didáctica de las Ciencias Sociales, etc.

PANTA REI is a digital journal focused on History and other sciences related to it. Its main objective is the transmission of scientific knowledge by giving also an opportunity to young researchers who want to make their way in the study of human and social sciences. It is composed by original studies related to History, as well as its didactics and promotion. The different sections of this journal are: research articles, interviews to professionals, recensions on monographs about current issues and reports about congresses or relevant scientific events.

All the articles published are subject to a revision process carried out by a minimum of two reviewers who are considered to be experts in the field of the article proposed. Our wish is to offer rigorous contents with quality and being of interest to the reader.

CEPOAT (Centre of Studies of the Middle East and Late Antiquity of the University of Murcia) is the institution in charge of the coordination and management of this journal. This is the centre from where the call for papers will be launched for all the people interested in publishing their papers, always related to History, Archeology, Art History, Didactics of the Social Sciences, etc. 


\section{Normas de Publicación}

El autor se compromete a enviar trabajos originales, que no se encuentren publicados en otras revistas ni en otros idiomas. Así mismo, el mismo artículo no podrá ser presentado en otras revistas mientras dure el proceso de evaluación.

\section{Envío y presentación de originales}

Los artículos se enviarán exclusivamente a través del correo electrónico a la dirección pantarei@um.es. Los textos serán enviados en formato DOC y las imágenes en formato JPEG o TIFF, y con un tamaño mínimo de 2000 px. Éstas no aparecerán incorporadas en el texto, sino enviadas en archivo aparte y correctamente numeradas según su posición en el texto. Junto al trabajo, se rellenará y enviará un documento aparte en el que se especifiquen los datos del autor siguiendo el modelo disponible en la página Web de la revista.

Para la redacción de los trabajos se tendrá en cuenta el Manual de la American Psychological Association, en su sexta edición. La extensión máxima de los trabajos será de 30 páginas. La tipografía será Arial 11, con interlineado sencillo y sin espacio alguno entre párrafos. El texto deberá ir justificado a ambos márgenes y sin sangría en los primeros párrafos. Los márgenes serán de $2,50 \mathrm{~cm}$. En los casos en los que fuera necesario incorporar notas, éstas irán a pie de página, enumeradas consecutivamente, con tipografía Arial 10, interlineado sencillo y justificadas a ambos márgenes.

Una información más detallada se encuentra disponible en la página http://www.um.es/cepoat/ pantarei.

\section{Proceso de valoración y evaluación}

Una vez recibidos los trabajos, la Revista realizará una primera valoración. Si el trabajo enviado se ajusta a las normas de presentación propuestas, la temática es coincidente con la línea editorial de la revista y posee la calidad científica necesaria, será remitido al consejo asesor para una primera evaluación. Si no es así en este primer paso se puede rechazar directamente los documentos que incumplan claramente la línea editorial.

Será el Consejo Asesor quien indique a la revista la originalidad, relevancia, estructura, redacción, aparato bibliográfico, etc. del trabajo enviado y, para ello, se designará a dos revisores expertos externos que evaluarán cada uno de los trabajos, que pueden formar parte (o no) de este Consejo Asesor. La selección de los revisores se ajustará a la temática y características metodológicas del trabajo. El nombre y filiación de los autores serán eliminados del trabajo para su revisión, así como los revisores actuarán de manera anónima y confidencial.

Los revisores deberán rellenar un informe de evaluación que centrará su atención en aspectos tales como características formales, originalidad y novedad de los trabajos, relevancia de las propuestas y los resultados, calidad metodológica y validez científica.

Una vez terminado el proceso se decidirá la aceptación o no de los mismos y su publicación en el número que sea pertinente, así como las modificaciones susceptibles de ser realizadas para su final publicación. Dicha notificación se enviará únicamente por correo electrónico, en un plazo máximo de seis meses. 


\section{Publishing rules}

The author is committed to submit original papers not having been published in other reviews or in other languages. In this way, it is not allowed for the same paper to be presented in other reviews during the evaluation process.

\section{Submission and presentation of originals}

The articles will be exclusively submitted by email to pantarei@um.es. The texts will be submitted in DOC format and the images in JPEG or TIFF format, and with a minimum size of 2000 px. Images will not be integrated in the text but sent in another file and properly numbered according to their position in the text. Attached to the paper, a document will be filled out and sent where the author's data will be specified following the model available on the website.

The sixth edition of the Manual of the American Psychological Association will be taken into account for the writing of the papers. The length of the papers must not exceed 30 pages. Typography will be Arial 11 , with simple line spacing and no space between paragraphs. The text must be justified on both margins without indentation in the first paragraphs. Margins size will be $2.50 \mathrm{~cm}$. Where it could be necessary the incorporation of notes, they will be at the bottom of the page, consecutively numbered with typography Arial 10, simple line spacing and justified on both margins.

More detailed information is available on the website: http://www.um.es/cepoat/pantarei.

\section{Examination and assessment process}

The Journal will submit the papers to a first examination once received. If the paper follows the presentation guidelines, the subject agrees with the editorial line of this journal, and possess the scientific quality required, it will be sent to the advisory council for a first assessment. If not, the documents which clearly fail to complete the editorial line may be rejected straightaway in this first step.

The Advisory Council will indicate the originality, relevance, structure, writing, bibliography, etc. of the text to the journal; for this purpose, two outside experts will be designated to review the papers; these experts can be (or not) part of this Advisory Council. The selection of the experts will adjust to the subject and methodological characteristics of the paper. Name and affiliation of the author will be eliminated from the text for its review, in this way experts will act anonymously and confidentially.

The experts will fill out an assessment report which will focus on aspects such as formal characteristics, originality and novelty of the papers, relevance and results of the proposal, methodological quality and scientific validity.

Once the process is finished, the acceptance or not of the papers and its publication in the corresponding edition will be decided, as well as the modifications that may be done for its final publication. This notification will be sent by email within 6 months maximum. 


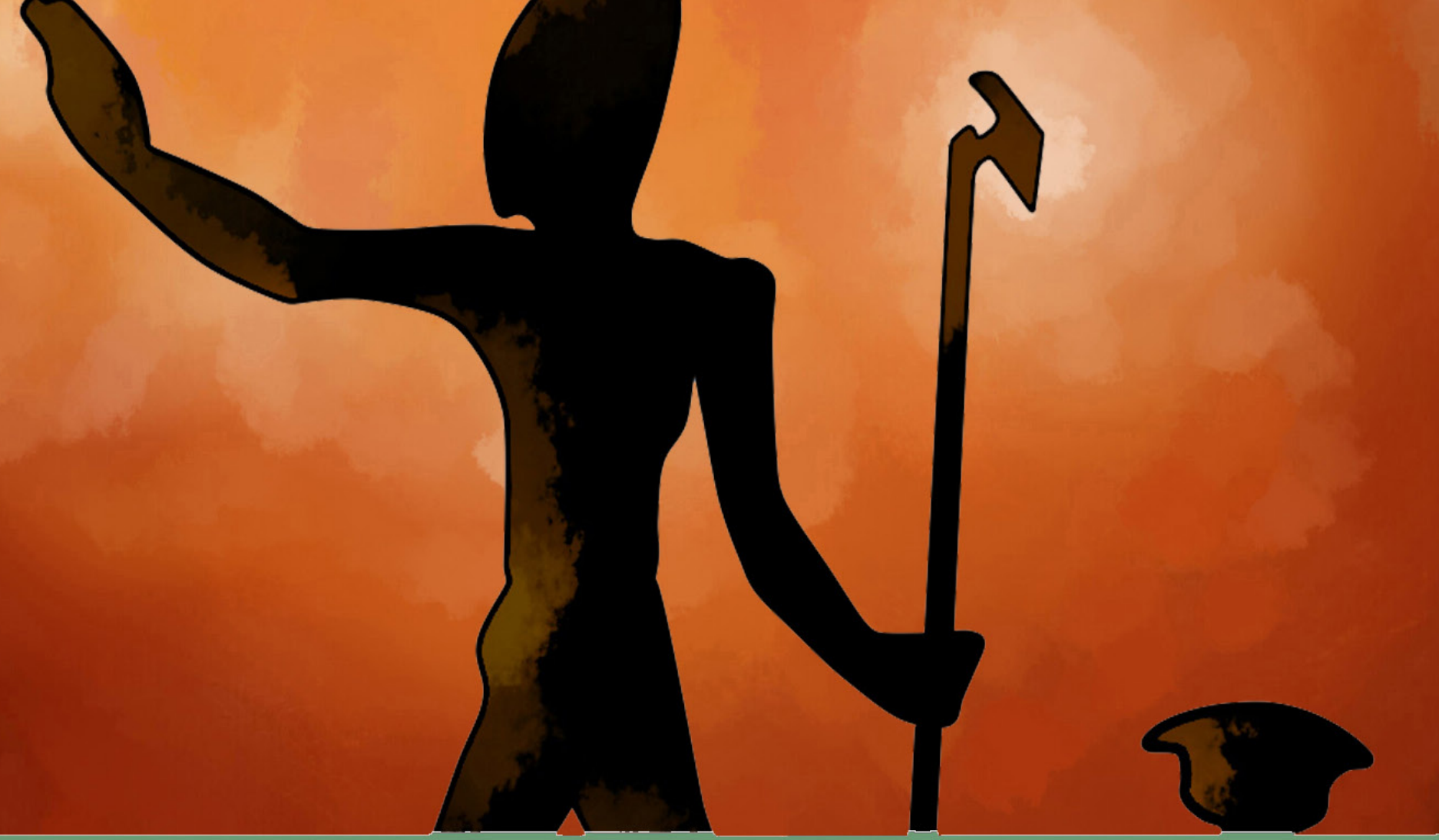

\section{cepot}

UNIVERSIDADD DE MURCIA

centro de estudios del

próximo oriente y la

antigüedad tardía 